\title{
Allicin suppressed bladder cancer cell biological activities via regulation of the miR-26b-5p/PTEN axis in an in vitro study
}

Hongwei Su${ }^{1}$, Xinjun $\mathrm{Qiao}^{2}$, Ting $\mathrm{Li}^{3}$, Chen $\mathrm{Li}^{1}$, Xin Liu ${ }^{1}$, Haibin Ling ${ }^{1}$, Xiangdong $\mathrm{Li}^{1}$

\author{
${ }^{1}$ Department of Urology, First Affiliated Hospital of Hebei North University, \\ Zhangjiakou, Hebei, China \\ 2Department of Chinese Orthopedics and Traumatology, Second Hospital \\ of Zhangjiakou City, Zhangjiakou, Hebei, China \\ ${ }^{3}$ Department of Drugs and Equipment, Second Hospital of Zhangjiakou City, \\ Zhangjiakou, Hebei, China
}

Submitted: 15 March 2020

Accepted: 4 April 2020

Arch Med Sci

DOI: https://doi.org/10.5114/aoms.2020.94919

Copyright $\odot 2020$ Termedia \& Banach

\section{Abstract}

Introduction: The aim of this study was to investigate the anti-tumour effects of allicin in bladder cancer and to elucidate the related mechanisms by performing an in vitro study.

Material and methods: Using the 5637 and T24 cell lines as model systems, the cell proliferation, apoptosis, cell invasion number and wound-healing rate were measured by MTT, flow cytometry, and Transwell and wound-healing assays. The expression of miR-26b-5p mRNA was evaluated by qRT-PCR assay, and relative protein expression (PTEN, PI3K and AKT) was evaluated by western blot assay. The correlation between miR-26b-5p and PTEN in 5637 and T24 cells was examined by the Dual Luciferase assay.

Results: Compared with the normal control (NC) group, cell proliferation was significantly depressed as apoptosis increased $(p<0.05)$, the invasion cell number and wound-healing rate were significantly suppressed with allicin treatment, and miR-26b-5p was significantly down-regulated in a dose-dependent manner $(p<0.05)$; PTEN was significantly up-regulated, and PI3K and AKT proteins were significantly down-regulated $(p<0.05)$ in the allicin-treated groups. With miR-26b-5p transfection, the cell biological activities of 5367 and T24 were significantly restored compared with the allicin-treated group $(p<0.05)$, with PTEN significantly depressed and PI3K and AKT significantly increasing in 5637 and T24 cells $(p<0.05)$.

Conclusions: Allicin has anti-tumour effects on bladder cancer cell biological activities, and the mechanism may involve regulation of the miR-26b-5p/ PTEN axis in bladder cancer cells.

Key words: 5637, T24, biological activities, miR-26b-5p, allicin, PTEN/PI3K/AKT.

\section{Introduction}

Bladder cancer is one of the most common tumours of the urogenital system in China and features a high incidence, rapid progression, high recurrence rate, etc. [1]. According to a study by the National Cancer Research Center, there were 78,000 new cases of bladder cancer in China in 2014, with an incidence of 57.1/100,000, 32,000 deaths, and a fatality rate of 23.5/100,000 [2]. Furthermore, in a recent study

\author{
Corresponding author: \\ Hongwei Su \\ Department of Urology \\ First Affiliated Hospital \\ of Hebei North University \\ Zhangjiakou \\ Hebei 075000, China \\ E-mail: suhongwei0824@163. \\ com
}


by the International Organization for Research on Cancer, the incidence of bladder cancer in the world in 2018 was 549,393, accounting for $3 \%$ of all cancers, and the death toll reached 199,992, accounting for $2.1 \%$ of all cancers [3]. Approximately $75 \%$ of new-onset cases are non-muscular-invasive bladder cancer (NMIBC) [4], and the 5 -year survival rate is $56 \%$ [5]. With the development of medical science, great progress has been achieved in the treatment of bladder cancer, but the survival rate of those patients has not reached a milestone in progress. Therefore, it is urgent to find new treatment strategies and effective interventions to improve the treatment of bladder cancer.

In recent decades, an increasing number of studies have been carried out on plant extracts, and many gratifying results have been achieved at the same time. Allicin has a long history as a prescription in Chinese traditional medicine. Recent studies have demonstrated that sulphur compounds in allicin are an important component for inhibiting and preventing tumours [6], which can inhibit cell growth and induce cell apoptosis through a variety of approaches and targets. Allicin is a complex of several allyl organic sulphides, one group of which consists of fat-soluble allyl sulphides, such as diallyl sulphide, diallyl disulphide, and diallyl trisulphide; the other consists of water-soluble compounds of $\gamma$-glutamine and S-allyl cysteine, such as S-allyl cysteine and S-allyl cysteamine [7]. Prior evidence has indicated that the high concentration of alliin extracted from garlic cannot inhibit cell growth by itself. However, the addition of garlic powder containing alliinase can inhibit the growth of cancer cells in a concentration-dependent manner. It is speculated that allicin may depend on its decomposition products, such as allicin and polysulfide, to exert its anti-tumour effects [8].

However, the effect of allicin on bladder cancer and its related mechanisms are still unclear. The present study was carried out to explore the effect of allicin on the biological activity of bladder cancer cells in vitro and its specific mechanisms.

\section{Material and methods}

\section{Materials}

Allicin injection (Shanghai Harvest Pharmaceutical Co., Ltd., 2 ml: 30 mg); bladder cancer cell lines 5637 and T24 (Shanghai Institute of Cell Biology, Chinese Academy of Sciences); RPMI-1640 medium and fetal bovine serum (FBS; Abcam Company, Cambridge, UK); 8 um Transwell chamber (CORNING); Lipofectamine 3000 transfection reagent (Invitrogen); primers and miR-26b-5p construction and synthesis (Jiangsu KeyGEN BioTECH Corp., Ltd.); MTT and DMSO (Sigma); Annexin V/PI apoptosis detection kit (Jiangsu KeyGEN BioTECH Corp., Ltd.); PTEN, PI3K, AKT and GAPDH polyclonal antibodies (Abcam, Cambridge, UK); DMSO (Sigma, USA).

\section{Cell culture and treatment}

Human bladder cancer cell lines 5637 and T24 were cultured in vitro after thawing and resuscitation. Cells in the logarithmic growth phase were divided into blank control, DMSO, and Allicin-low, -medium and -high (dissolved in DMSO at concentrations of $12.5,25$ and $50 \mu \mathrm{g} / \mathrm{ml}$ ) groups. Twelve replicates were made for each group, followed by testing $48 \mathrm{~h}$ later.

\section{Cell transfection}

Following culturing, 5637 and T24 bladder cancer cells under good growth conditions were taken when the cell density reached $60-70 \%$, followed by cell transfection with miR-NC and miR-26b-5p, respectively, using Lipofectamine 3000 . Transfection was carried out according to the instructions of the liposome kit, and the transfection concentration was $50 \mathrm{nmol} / \mathrm{l}$.

\section{Detection of miR-26b-5p expression in cells of each group by qRT-PCR}

Bladder cancer cells were collected from each group, total RNA was extracted using TRIzol reagent (Invitrogen, Carlsbad, CA, USA), and cDNA was synthesized with the miRNA reverse transcription kit (Takara, Tokyo, Japan). All procedures were carried out according to the manufacturers' instructions. The following reverse transcription conditions were used: incubation at $37^{\circ} \mathrm{C}$ for $60 \mathrm{~min}$, incubation at $85^{\circ} \mathrm{C}$ for $5 \mathrm{~S}$, and reaction termination at $4^{\circ} \mathrm{C}$. The obtained CDNA was then dissolved with DEPC-treated water for PCR detection. U6 was the internal reference of quantitative $P C R$, and the calculation method was $2^{-\Delta \Delta C t}$. The sequence of the primers is shown in Table I.

Table I. Primer sequences

\begin{tabular}{|lr|}
\hline Gene name & \multicolumn{1}{c|}{ Sequence } \\
\hline miR-26b-5p & 5'-UCAAGUAAUUCAGGAUAGGU-3' \\
\hline U6 & F: 5'-GGAACGATACAGAGAAGATTAGC-3' \\
& R: 5'-TGGAACGCTTCACGAGAATTTGCG-3' \\
\hline
\end{tabular}




\section{MTT assay for cell proliferation}

Cells in each group were digested with trypsin, homogenized into a single-cell suspension, and then inoculated into a 96-well plate $(n=10)$ after the concentration was adjusted to $5 \times 10^{4} / \mathrm{ml}$. Following further culture for $24 \mathrm{~h}, 20 \mu \mathrm{l}$ of MTT was added to each well and then cultured for another $4 \mathrm{~h}$, followed by the addition of $150 \mu \mathrm{l}$ of DMSO and incubation with shaking for $10 \mathrm{~min}$ in the dark. After that, the absorbance (A) at $490 \mathrm{~nm}$ was measured on a microplate reader, and the cell proliferation rate was calculated.

\section{Flow cytometry for detection of cell apoptosis}

Cells were digested, suspended, and centrifuged, followed by removal of the supernatant. Phosphate buffer was used to wash the supernatant three times, and $200 \mu \mathrm{l}$ of Annexin V-FITC binding buffer was added to the supernatant to suspend the cells gently. The cells were incubated at room temperature for $10 \mathrm{~min}$ in the absence of light. After centrifugation for $5 \mathrm{~min}$, the supernatant was discarded; another $190 \mu$ l of Annexin V-FITC binding buffer was added to suspend the cells gently; $10 \mu \mathrm{l}$ of PI dye was added to mix the cells gently, and apoptotic cells were detected by flow cytometry.

\section{Transwell assay for detection of cell invasion}

Cells were subcultured in a Transwell chamber containing pre-coated matrix glue, with the cell density adjusted to $1 \times 10^{5}$ cells $/ \mathrm{ml}$. The cells were cultured in serum-free medium containing $0.2 \%$ bovine serum albumin, and 20\% FBS medium was added to the lower layer of the chamber. After $48 \mathrm{~h}$ of culture, the cells in the chamber were wiped off with sterile cotton swabs and stained with crystal violet. The cells that invaded the lower layer of the chamber were counted with 10 visual fields randomly selected from each well, with 3 replicates in each group. The experiment was repeated three times.

\section{Wound healing assay}

Five parallel lines were drawn on the back of a 12-well cell culture plate with a marker pen one day before the experiment. After ultraviolet disinfection and sterilization, samples were placed in a sterile environment for preservation. On the second day, cells in the logarithmic growth phase were digested and subcultured in a 12-well cell culture plate prepared in advance, with the cell density adjusted to $1 \times 10^{5}$ cells $/ \mathrm{ml}$. After $4 \mathrm{~h}$ of transfection, the tip of a $10 \mathrm{ml}$ pipette was used to scratch perpendicular to the back of a 12-well cell culture plate. Following three washes with phosphate buffer, FBS-free medium was added for a further $24 \mathrm{~h}$ of culture. Three visual fields were randomly selected for photography under an inverted fluorescence microscope at 0, 24 and $48 \mathrm{~h}$, respectively, followed by recording and statistical analysis.

\section{Western blotting for detection of PTEN, $\mathrm{PI} 3 \mathrm{~K}$ and AKT protein expression}

Cells were digested by trypsinase and centrifuged. After 30 min of freezing by adding an appropriate amount of cold lysis solution, the cells were shattered by ultrasound for $10 \mathrm{~s}$. Protein was isolated by centrifugation $\left(13000 \mathrm{r} / \mathrm{min}, 4^{\circ} \mathrm{C}\right.$, $20 \mathrm{~min})$. After protein separation, quantitative analysis of protein was achieved by the BCA method and then denaturation at high temperature. After electrophoresis, transfer to PVDF membranes and ponceau S staining, and blocking with 5\% skimmed milk powder for $2 \mathrm{~h}$, the primary antibodies PTEN (1 : 500), PI3K (1 : 500), AKT (1 : 500) and GAPDH $(1: 1000)$ were added and incubated at $4^{\circ} \mathrm{C}$ overnight. Following three washes in PBS, the secondary antibody $(1: 100)$ was added and incubated at room temperature for $1 \mathrm{~h}$, followed by developing. After that, the expression of PTEN, PI3K and AKT was semi-quantitatively analysed according to the grey value of electrophoretic bands.

\section{Dual luciferase reporter assay for detection of target sites of PTEN regulated by miR-26b-5p}

The wild-type PTEN 3'UTR-luciferase reporter vector was named PTEN-Wt, and the mutant-type PTEN 3'UTR-luciferase reporter vector was named PTEN-Mut. In accordance with the manufacturer's instructions for Lipofectamine 2000, Luciferase reporter vectors, as well as miR-26b-5p mimics and control miR-NC sequences, were co-transfected with 5367 and T24 cells in each group according to the group results for the experiment. After $48 \mathrm{~h}$ of treatment, the cells were harvested, and the luciferase activity of the treated cells was detected according to the instructions of Promega's dual luciferase reporter gene detection kit, associated with the calculation of relative luciferase activity (the activity of firefly luciferase/the activity of Renilla luciferase).

\section{Statistical analysis}

SPSS 15.0 statistical software was used for statistical analysis in this experiment, Measurement data were expressed as mean \pm SD. The mean comparison among multiple groups was performed by one-way analysis of variance (ANOVA), 
and the LSD $t$-test was used for further pairwise comparisons. Differences were considered statistically significant at $p<0.05$.

\section{Results}

\section{Effect of allicin on proliferation and apoptosis of bladder cancer cells}

After the intervention on bladder cancer 5637 and T24 cells at different concentrations of allicin, the morphology of both types of cells did not change significantly in each group. The results indicated that the cell morphology of 5637 and T24 cells did not change significantly when allicin was provided at low, medium and high concentrations $(12.5,25$ and $50 \mu \mathrm{g} / \mathrm{ml}$ ) (Figures $1 \mathrm{~A}, \mathrm{~B})$. Furthermore, MTT assay showed that there was no obvious difference between the DMSO group and the NC group, indicating that DMSO was non-toxic to bladder cancer cells. The proliferation rates of 5367 and T24 cells in the allicin treatment group were significantly decreased (both $p<0.05$, Figures $1 \mathrm{~A}, \mathrm{~B}$ ), and there was a remarkable dose-effect relationship among allicin treatment groups $(p<0.05$, Figures $1 \mathrm{~A}, \mathrm{~B})$. In addition, flow cytometry revealed no notable difference between the DMSO group and the NC group, suggesting the non-toxicity of DMSO to bladder cancer cells, while the apoptotic rates of 5367 and T24 cells in the allicin treatment groups increased significantly ( $p<0.05$, Figures 2 A, B), and a significant dose-effect relationship was also observed among allicin treatment groups ( $p<0.05$, Figures 2 A, B).

\section{Effect of allicin on invasion and migration of bladder cancer cells}

The invasion and migration of bladder cancer 5637 and T24 cells were detected by Transwell and wound-healing assays, respectively. Compared with the NC group, the number of invasive cells and the wound-healing rate in the DMSO group of 5367 and T24 cells did not differ significantly, indicating that DMSO had no effect on invasion and migration in bladder cancer 5637 and T24 cells. Simultaneously, compared with the NC group, the number of migrating 5367 and T24 cells and the wound-healing rate were significantly inhibited in the allicin treatment groups ( $p<0.05$, Figures 3,4$)$, and a dose-effect relationship was also evident among allicin treatment groups ( $p<0.05$, Figures 3,4$)$.

\section{Effects of allicin on expression of miR-26b-} $5 \mathrm{p}$ mRNA and related proteins

qRT-PCR and WB assays showed no significant difference in miR-26b-5p mRNA levels as well as PTEN, PI3K and AKT protein expression between NC and DMSO groups in 5637 and T24 cells (Fig- ures 5,6$)$. Compared with the NC group, expression levels of miR-26b-5p mRNA as well as PI3K and AKT proteins in the allicin treatment groups were significantly lower $(p<0.05$, respectively, Figures 5,6$)$, while the expression level of PTEN protein was significantly higher $(p<0.05$, Figures $5,6)$. Meanwhile, expression levels of miR-26b$5 p$ mRNA, as well as those of PTEN, PI3K and AKT proteins in 5367 and T24 cells treated with allicin showed a significant dose-effect relationship $(p<0.05$, Figures 5,6$)$

\section{Differential expression of miR-26b-5p mRNA in different groups}

Compared with the NC group, there was no significant difference in the expression of miR-26b-5p mRNA in the miR-NC group with 5637 and T24 cells transfected with blank vectors $(p>0.05)$, but the expression level of miR-26b-5p mRNA in the allicin group was significantly inhibited $(p<0.001$, Figures $7 \mathrm{~A}, \mathrm{~B})$. After treatment with allicin and transfection with miR-26b-5p at the same time, the expression level of miR-26b-5p mRNA in the allicin + miR-26b$5 p$ group was significantly higher than that in the allicin group $(p<0.001$, Figures 7 A, B).

\section{Role of microRNA-26b-5p in allicin-induced} cell proliferation and apoptosis

Compared with the NC group, there was no significant difference in cell proliferation and apoptosis in the miR-NC group with 5637 and T24 cells transfected with blank vectors $(p>0.05)$. After allicin treatment, 5637 and T24 cells showed a significant increase in the apoptotic rate and a significant decrease in the proliferation rate $(p<0.001$, Figures 8,9$)$. After simultaneous treatment with allicin and transfection with miR-26b-5p, allicin + miR-26b-5p showed significantly higher cell proliferation and a significantly lower apoptotic rate when compared with the allicin group $(p<0.001$, Figures 8, 9).

\section{Role of microRNA-26b-5p in Allicin-} inhibited cell invasion and migration

Compared with the NC group, there was no significant difference in the number of invasive cells or the wound-healing rate in the miR-NC group with 5637 and T24 cells transfected with blank vectors $(p>0.05)$. Compared with the NC group, the number of invasive cells and the wound-healing rate were significantly inhibited in the allicin group after allicin treatment $(p<0.001$, Figures 10 11). Furthermore, compared with the allicin group, the number of invasive cells and wound-healing rate in the allicin + miR-26b-5p group was significantly higher after miR-26b-5p was transfected into cells $(p<0.001$, Figures 10,11$)$. 
A

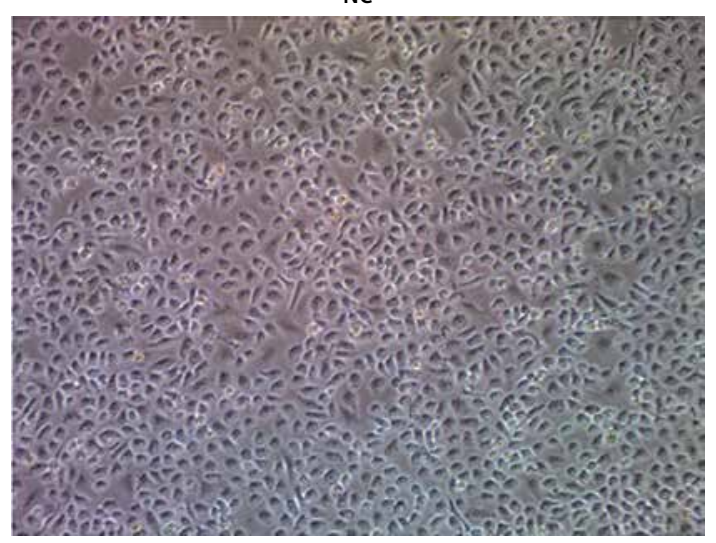

Allicin-L

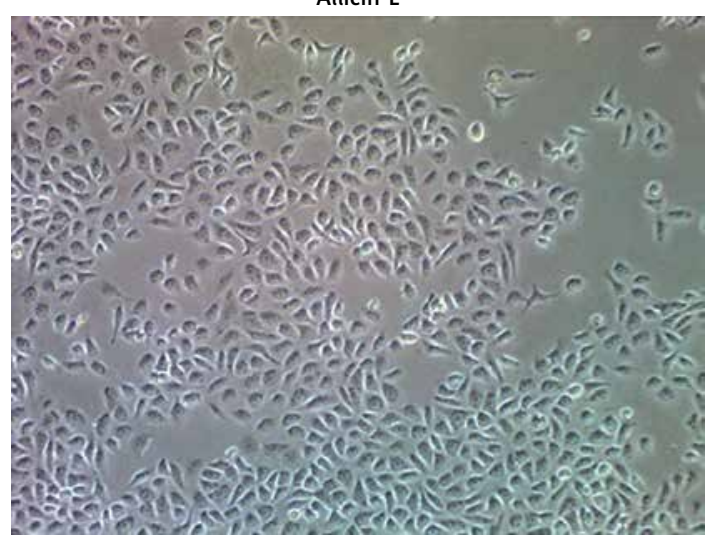

Allicin-H

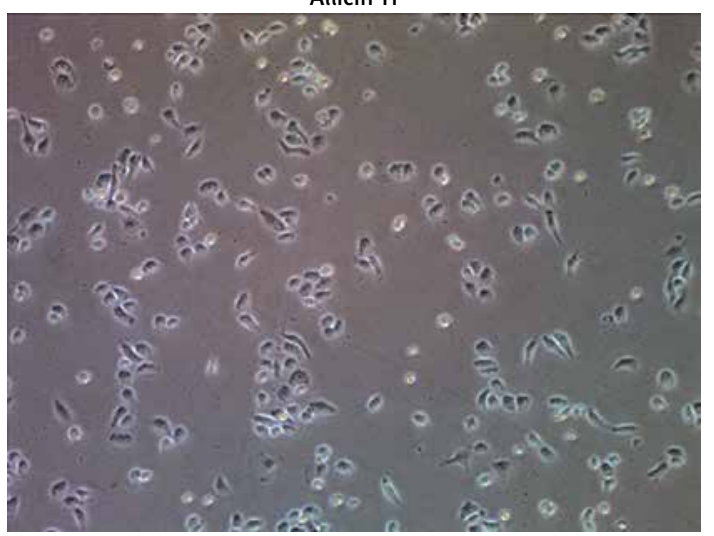

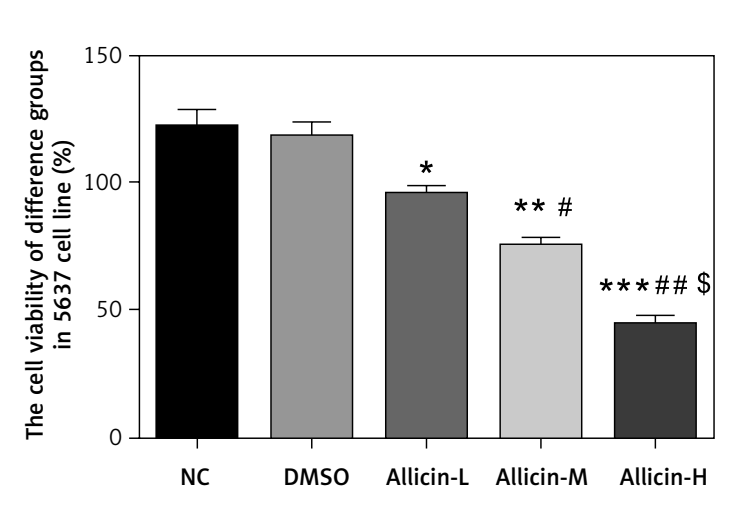
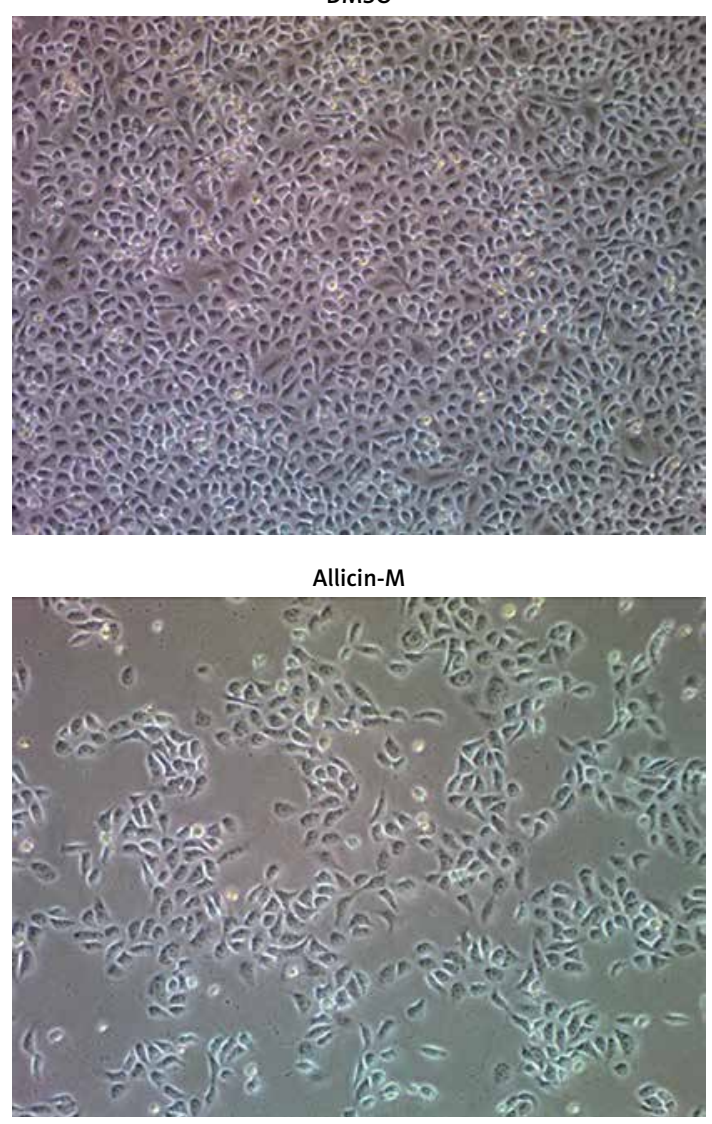

Figure 1. Allicin effect on cell proliferation of different groups in 5637 and T24 cell lines (100x). NC - The cells were treated with normal treatment, DMSO - The cells were treated with DMSO, Allicin-L - The cells were treated with $12.5 \mu \mathrm{g} / \mathrm{ml}$ allicin which was dissolved in DMSO; Allicin- $M$ - The cells were treated with $25 \mu \mathrm{g} / \mathrm{ml}$ allicin which was dissolved in DMSO; Allicin-M - the cells were treated with $50 \mu \mathrm{g} / \mathrm{ml}$ allicin which was dissolved in DMSO. A - Allicin effect on cell proliferation of different groups in $5637(100 \times)$

${ }^{*} P<0.05 ;{ }^{* *} p<0.01,{ }^{* *} p<0.001$, compared with NC group; ${ }^{*} p<0.05 ;{ }^{* \#} p<0.01$, compared with Allicin-L group; ${ }^{s} p<0.05$, compared with Allicin-M.

\section{Expression of related proteins and} correlation between miR-26b-5p and PTEN in 5637 and T24 cells

In view of the relative protein expression results obtained by WB, compared with the NC group, there was no significant difference in PTEN, PI3K and AKT 
B

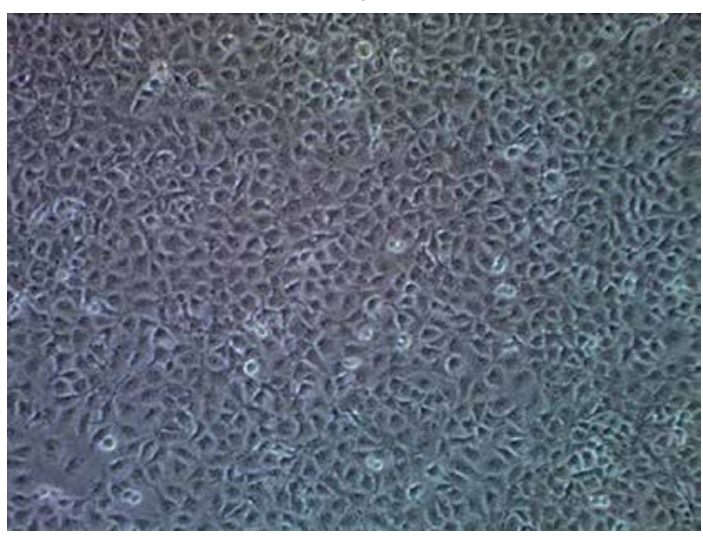

Allicin-L

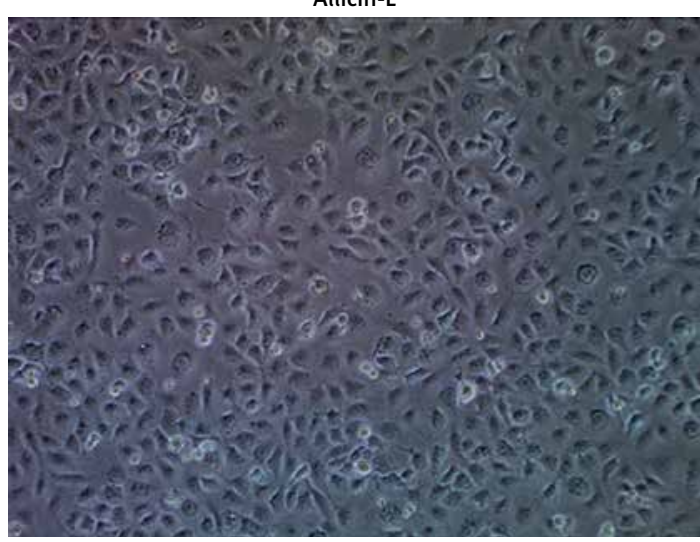

Allicin-H

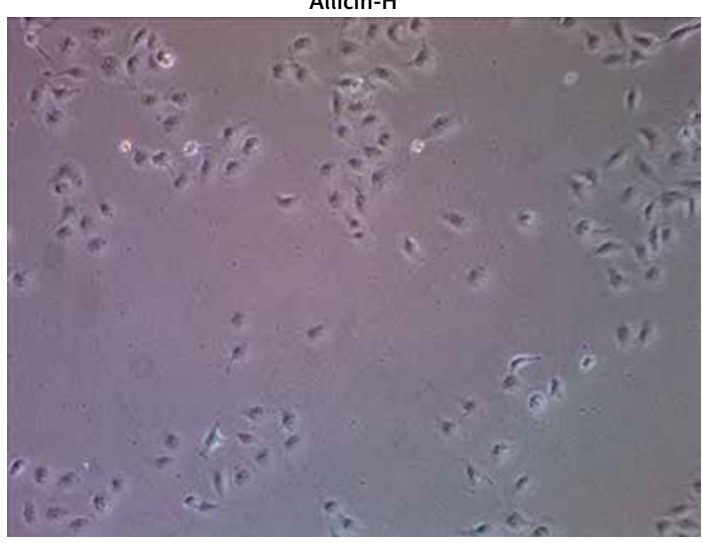

DMSO

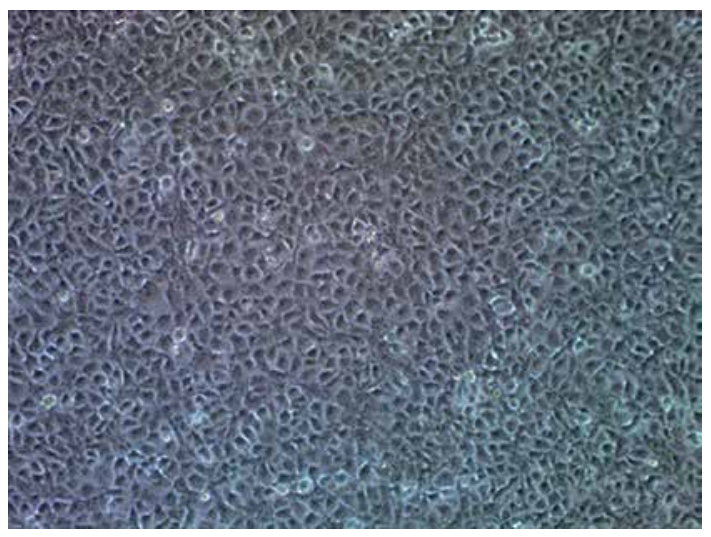

Allicin-M
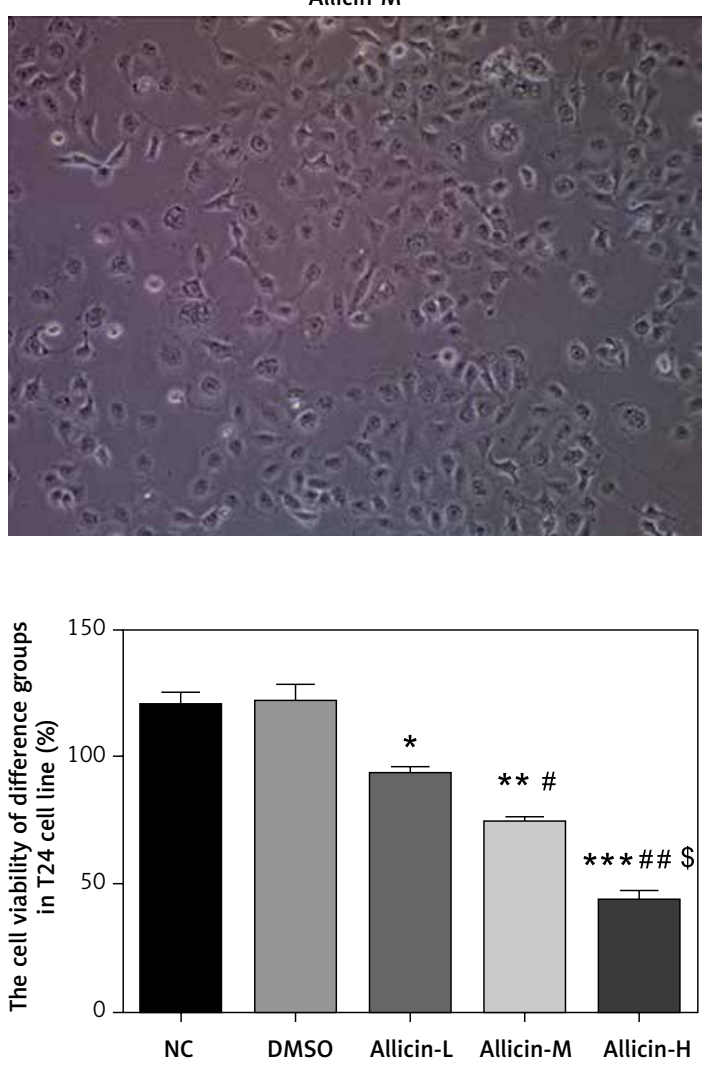

Figure 1. Cont. B - Allicin effect on cell proliferation of different groups in T24 (100x)

${ }^{\star} p<0.05 ;{ }^{* *} p<0.01,{ }^{* *} p<0.001$, compared with NC group; ${ }^{*} p<0.05 ;{ }^{* \#} p<0.01$, compared with Allicin-L group; ${ }^{5} p<0.05$, compared with Allicin-M.

compared with the allicin group, the expression of PTEN was significantly higher in the allicin + miR-26b$5 p$ group, while the expression of PI3K and AKT was clearly inhibited ( $p<0.001$, Figure 12). Dual luciferase assay showed that in 5637 and T24 cells, miR-26b-5p could target PTEN expression ( $p<0.001$, Figure 13).

\section{Discussion}

Allicin is a natural sulphur-containing compound extracted from garlic, which is synthesized by alliin (S-allyl cysteine sulfoxide), a non-protein amino acid, catalysed by alliinase, and is the main source of fresh garlic odour [9]. As a thiosulfate, allicin can react with glutathione and sulfhydryl groups in proteins, and has strong biological activity in microorganisms, plants and animal cells [10]. Allicin has been reported to have several pharmacological effects, such as anti-inflammation, anti-oxidation, anti-microbial properties, etc. It also has the effects of lowering blood pressure, 
A

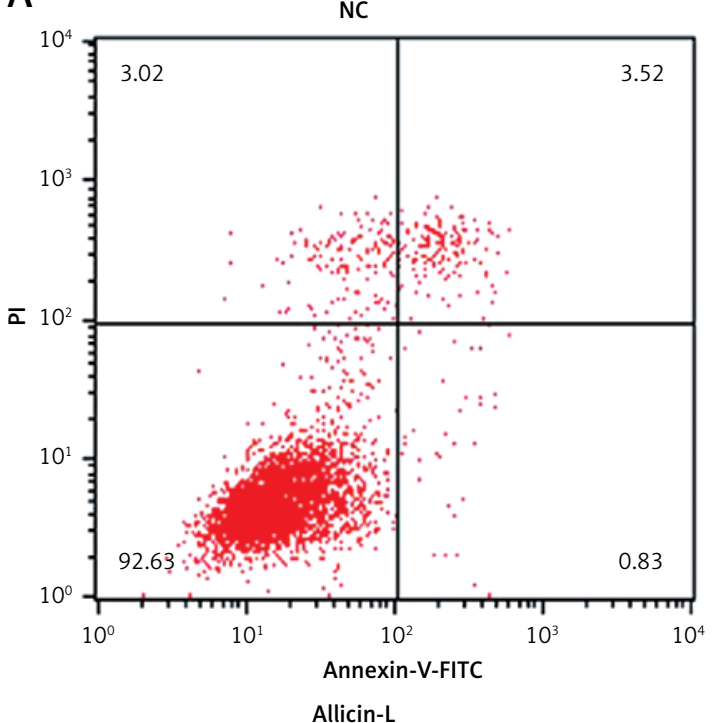

Allicin-L

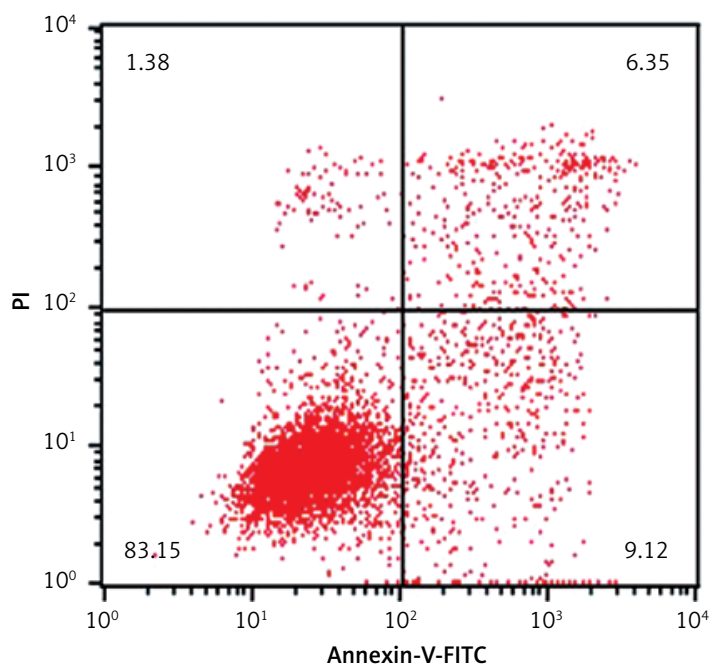

Annexin-V-FITC

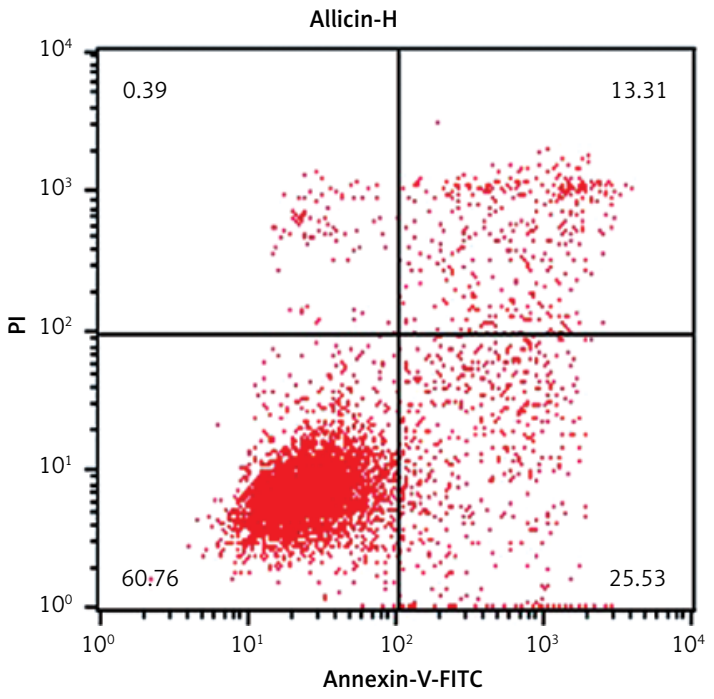

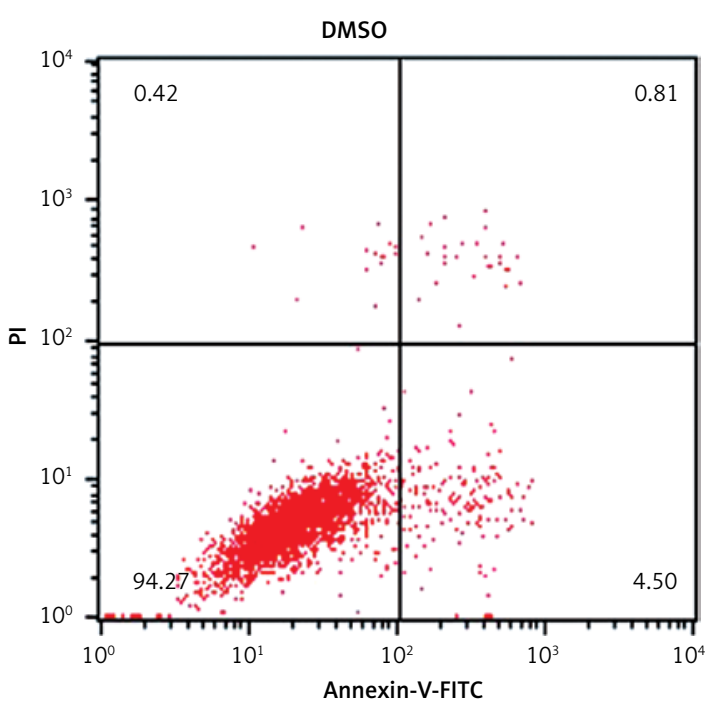

Allicin-M
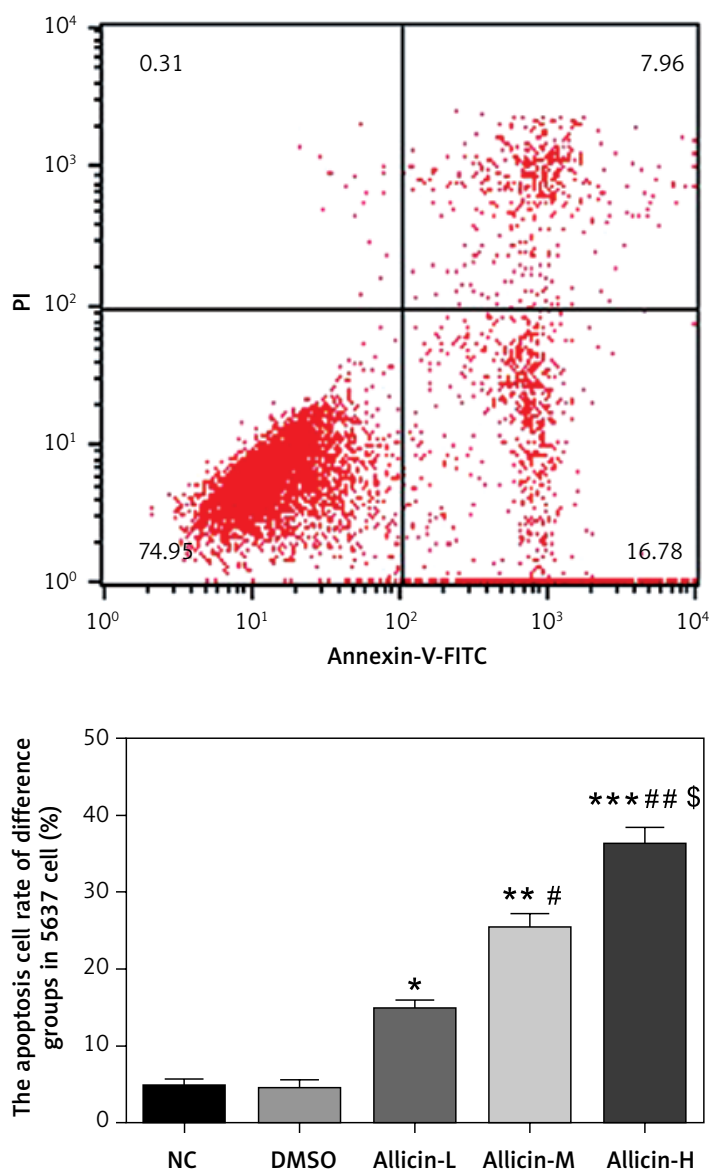

Figure 2. Allicin effect on cell apoptosis of different groups in 5637 and T24 cell lines. NC - The cells were treated with normal treatment; DMSO - the cells were treated with DMSO; Allicin-L - the cells were treated with $12.5 \mu \mathrm{g} / \mathrm{ml}$ allicin which was dissolved in DMSO; Allicin-M - the cells were treated with $25 \mu \mathrm{g} / \mathrm{ml}$ allicin which was dissolved in DMSO; Allicin-M - the cells were treated with $50 \mu \mathrm{g} / \mathrm{ml}$ allicin which was dissolved in DMSO. A - Allicin effect on cell proliferation of different groups in 5637

${ }^{*} p<0.05 ;{ }^{* *} p<0.01,{ }^{* *} p<0.001$, compared with NC group; ${ }^{*} p<0.05 ;{ }^{* \#} p<0.01$, compared with Allicin-L group; ${ }^{s} p<0.05$, compared with Allicin-M. 

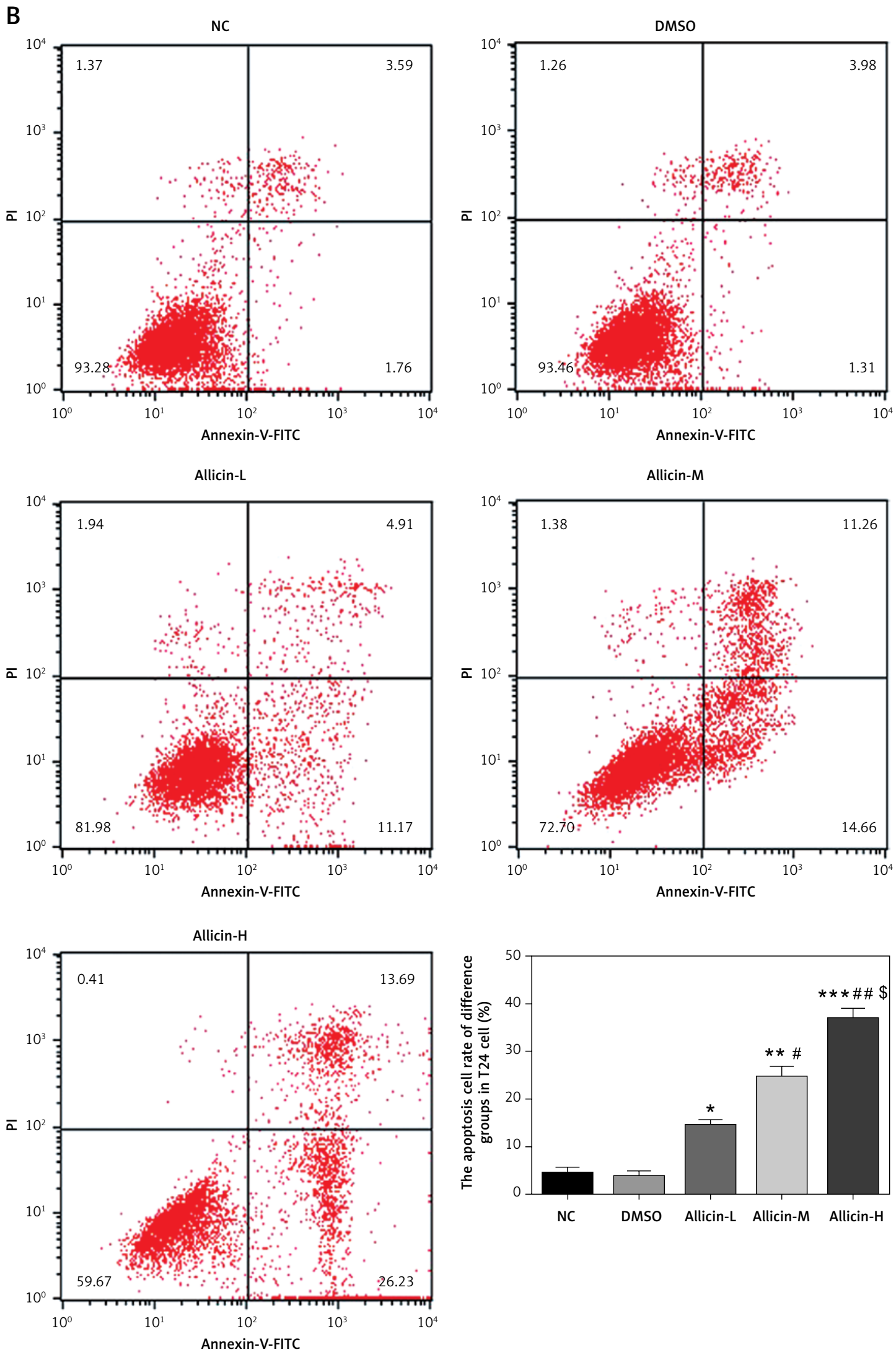

Figure 2. Cont. B - Allicin effect on cell proliferation of different groups in T24

${ }^{*} p<0.05 ;{ }^{* *} p<0.01,{ }^{* * *} p<0.001$, compared with NC group; ${ }^{*} p<0.05 ;{ }^{\# *} p<0.01$, compared with Allicin-L group; ${ }^{s} p<0.05$ compared with Allicin-M. 
A

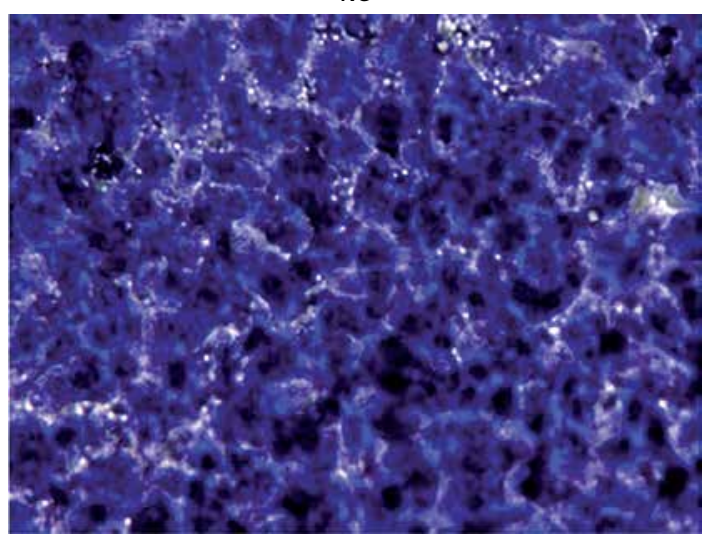

Allicin-L

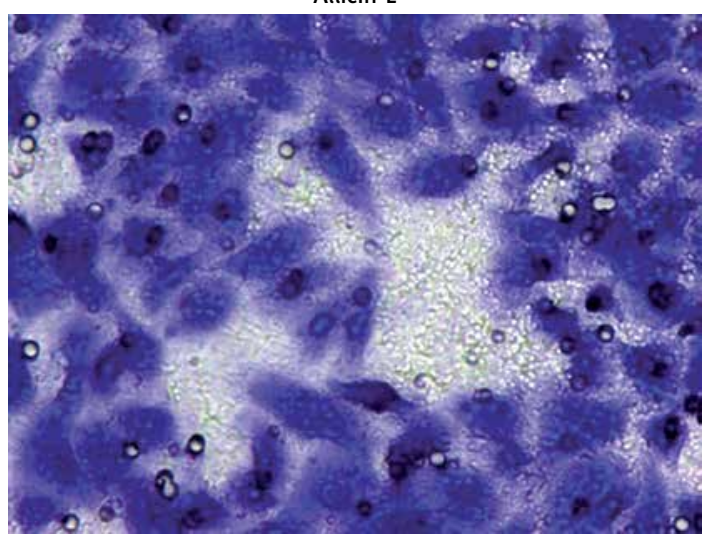

Allicin-H

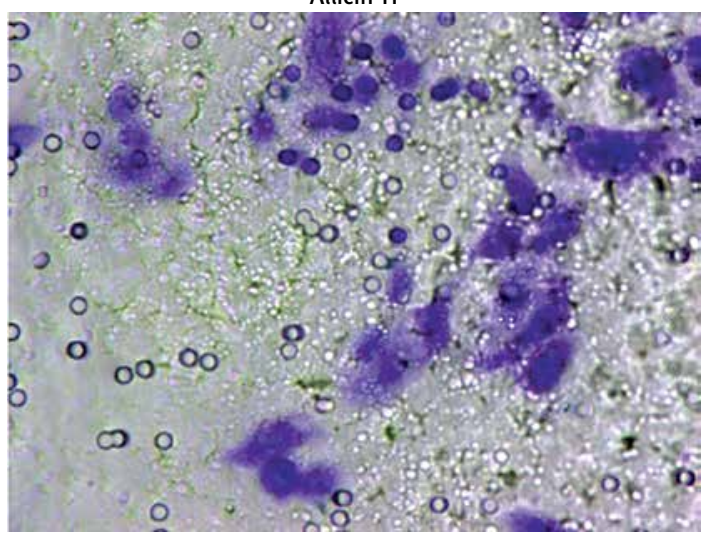

DMSO

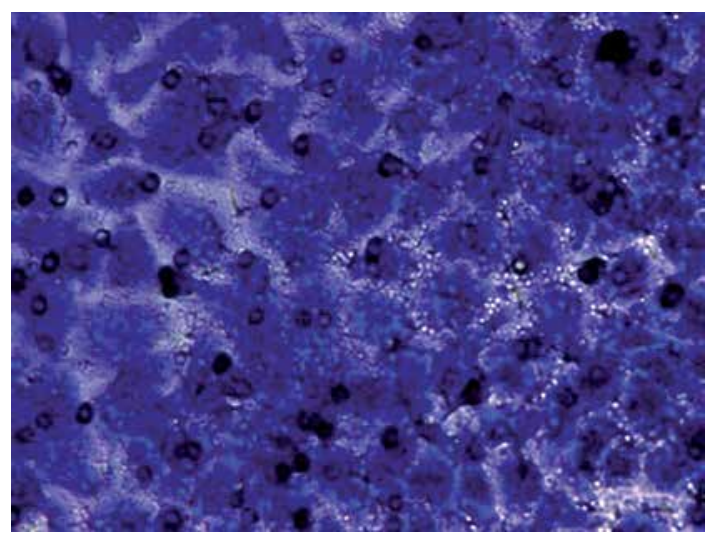

Allicin-M
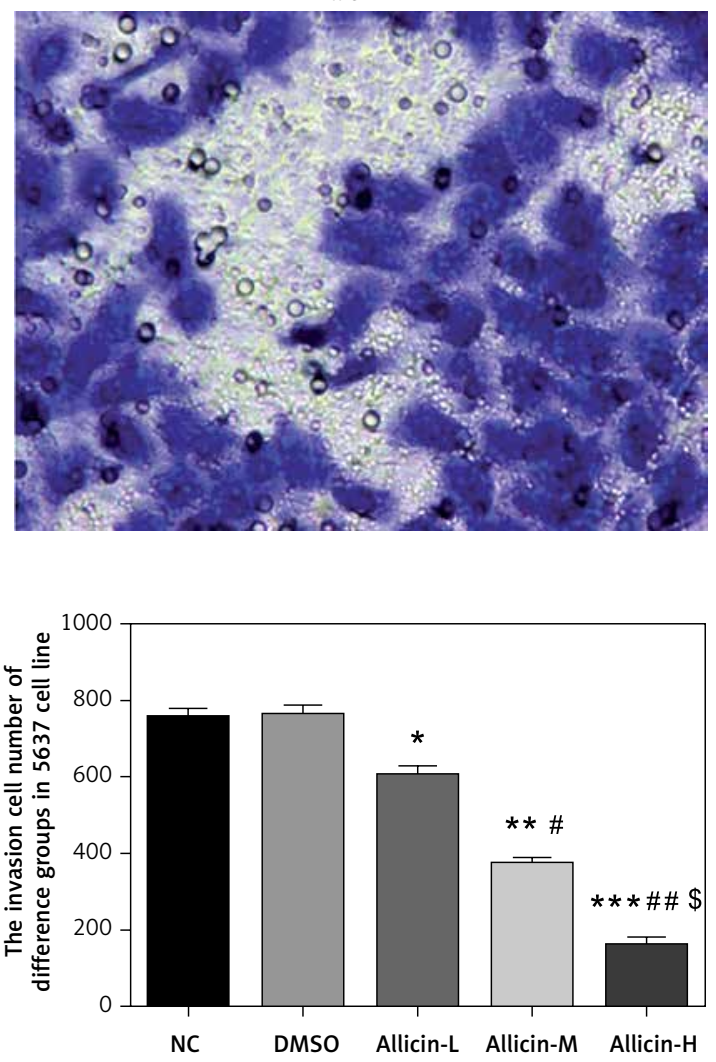

Figure 3. Allicin effect on invasion cell number of different groups by transwell assay (200x). NC - The cells were treated with normal treatment; DMSO - the cells were treated with DMSO; Allicin-L - the cells were treated with $12.5 \mathrm{\mu g} / \mathrm{ml}$ allicin which was dissolved in DMSO; Allicin-M - the cells were treated with $25 \mu \mathrm{g} / \mathrm{ml}$ allicin which was dissolved in DMSO; Allicin-M - the cells were treated with $50 \mu \mathrm{g} / \mathrm{ml}$ allicin which was dissolved in DMSO. A - Allicin effect on invasion cell number of different groups in 5637 cell lines by transwell assay (200x)

${ }^{*} P<0.05 ;{ }^{* *} p<0.01 ;{ }^{* * *} p<0.001$, compared with NC group; ${ }^{*} p<0.05 ;{ }^{* \#} p<0.01$, compared with Allicin-L group; ${ }^{s} p<0.05$, compared with Allicin-M.

lowering blood lipids and improving microcirculation, which have been widely used in clinical practice [11-13]. Previous studies have demonstrated that allicin has a strong anti-tumour effect, can significantly inhibit the proliferation of hepatocellular carcinoma, gastric cancer, ovarian cancer and other cancer cells, but exerts quite a low cytotox- ic effect on normal tissues [14-16]. As evidenced by a prior study, allicin can induce cell apoptosis via the mitochondrial pathway and inhibit the proliferation of human leukaemia HL-60 cells and human histiocytic lymphoma U937 cells [17]. The results of this study showed that allicin could effectively inhibit the biological activity of bladder 
B

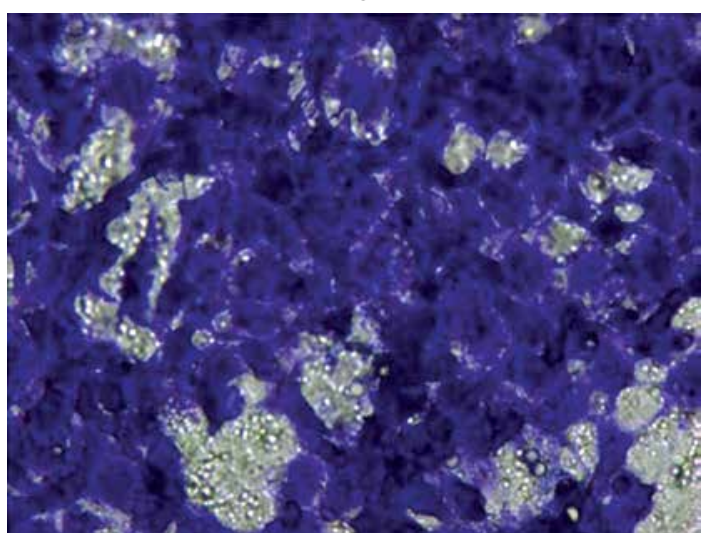

Allicin-L
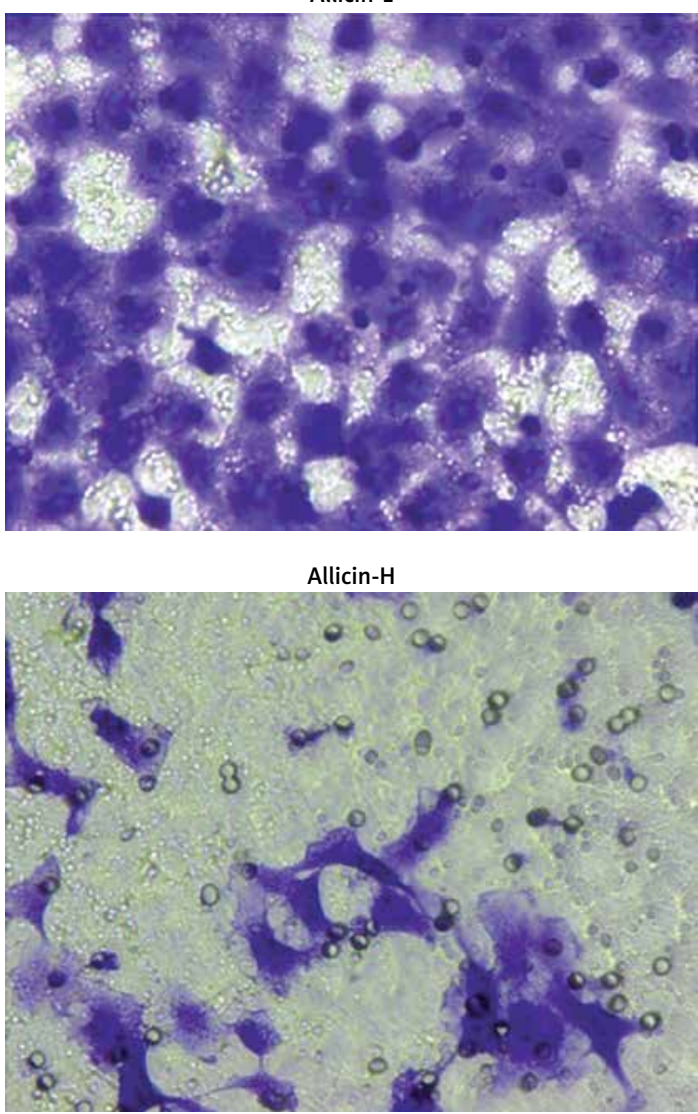

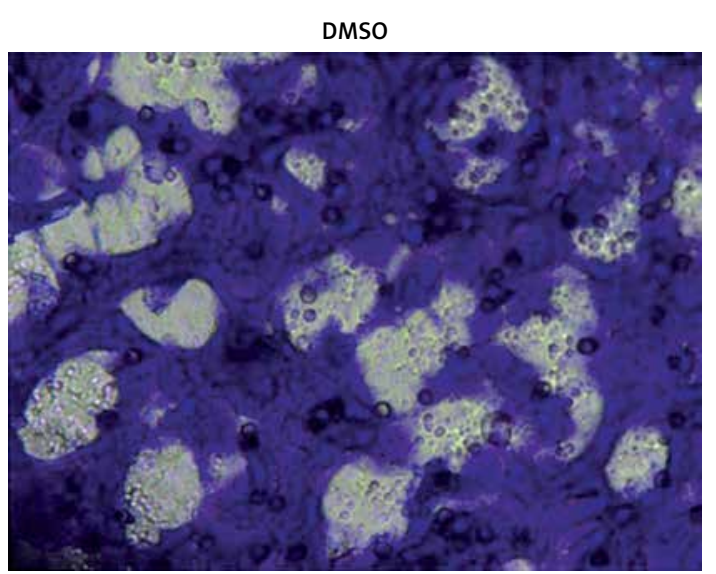

Allicin-M
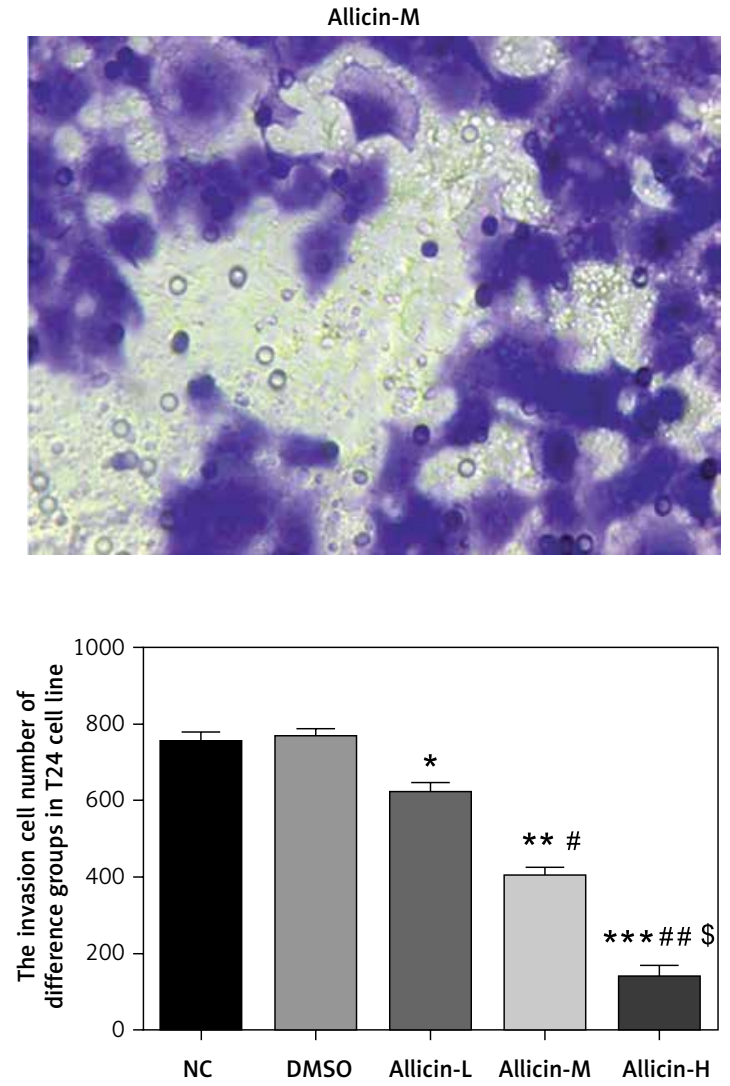

Figure 3. Cont. B - Allicin effect on invasion cell number of different groups in T24 cell lines by transwell assay $(200 x)$

${ }^{\star} P<0.05 ;{ }^{* *} p<0.01 ;{ }^{* *} p<0.001$, compared with NC group; ${ }^{*} p<0.05 ;{ }^{\# \#} p<0.01$, compared with Allicin-L group; ${ }^{s} p<0.05$, compared with Allicin-M.

cancer in a significant dose-dependent manner. Moreover, the inhibitory effect on the activity of bladder cancer cells peaked when the concentration of allicin reached $50 \mu \mathrm{g} / \mathrm{ml}$. Meanwhile, the results also showed that the expression level of miR-26b-5p decreased significantly with the increase in allicin concentration.

MicroRNAs (miRNAs) consist of short RNA segments 19-25 nucleotides in length, which can regulate gene expression at the post-transcrip- tional level and participate in various biological behaviours such as cell proliferation, differentiation, apoptosis, aging and metastasis $[18,19]$. Increasingly, many studies have shown that miRNAs play an important regulatory role in the occurrence and development of bladder cancer. Research on the mechanism of action of miRNAs has become the focus of research in the field of bladder cancer $[20,21]$. For example, the expression of some miRNAs, such as miR-497 [22], miR-139-5p [23] 
A

NC

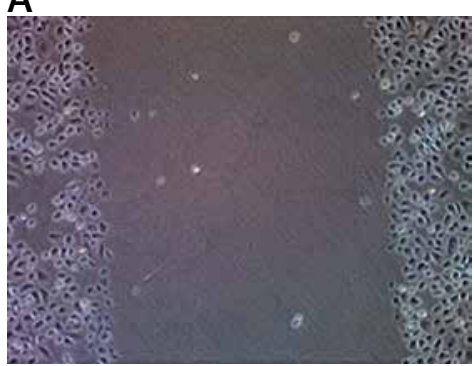

DMSO
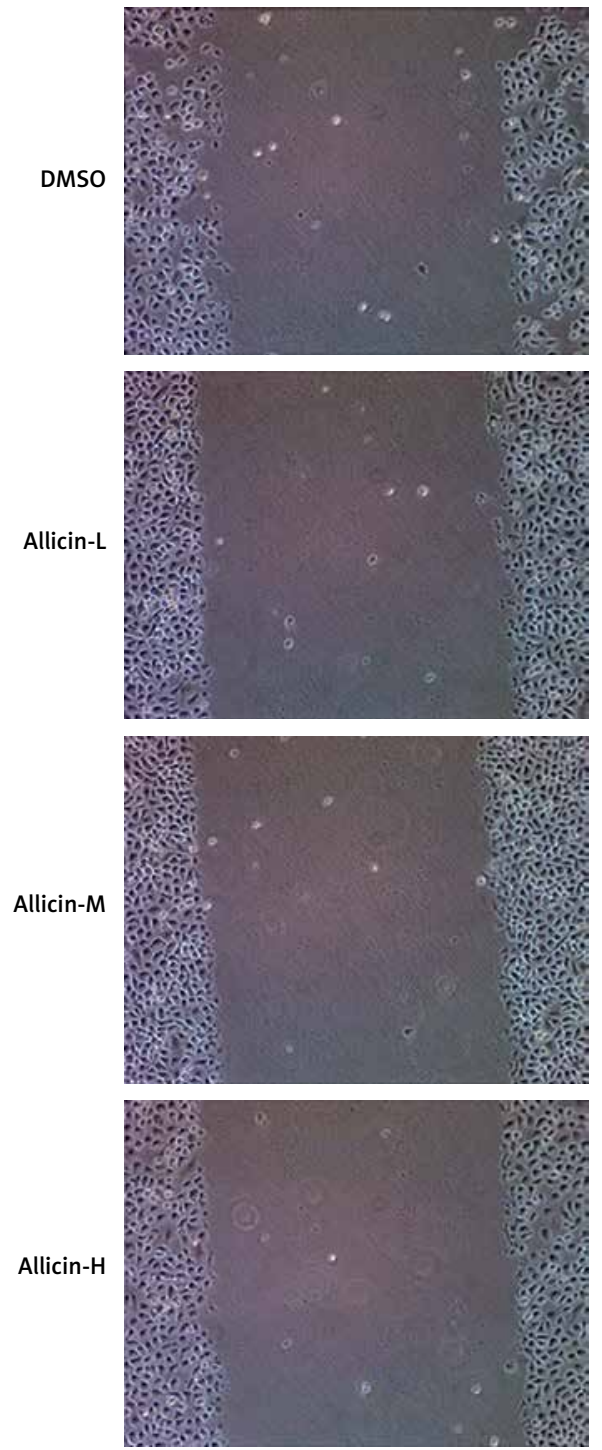

$24 \mathrm{~h}$
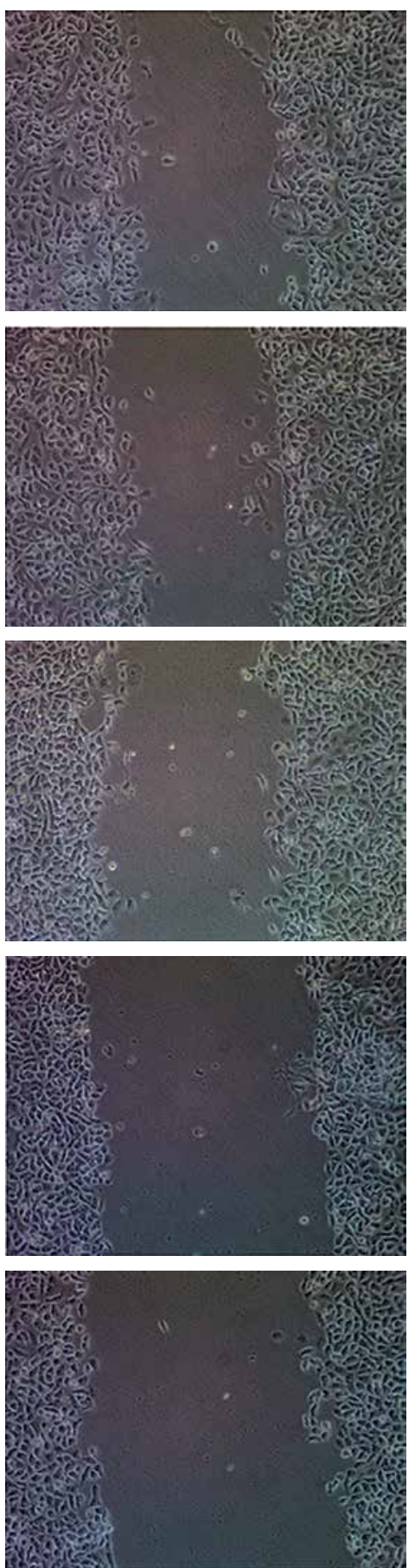

$48 \mathrm{~h}$
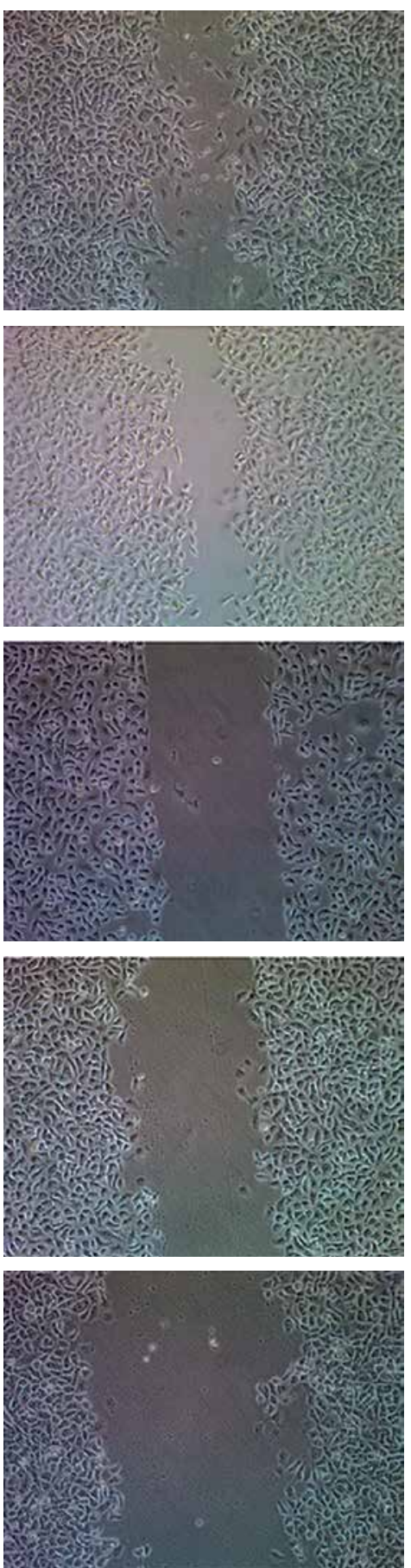

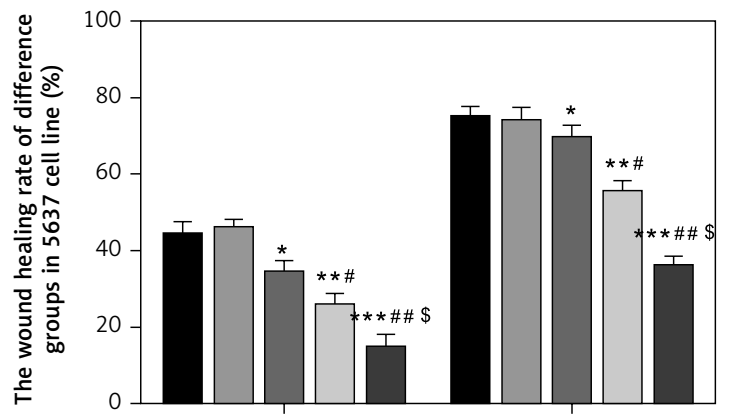

$24 \mathrm{~h}$

$48 \mathrm{~h}$

- NC $\square$ DMSO $\square$ Allicin-L $\square$ Allicin-M

allicin-H

Figure 4. Allicin effect on wound healing rate of different groups by wound healing assay (100x). NC - the cells were treated with normal treatment; DMSO - the cells were treated with DMSO; Allicin-L - the cells were treated with $12.5 \mathrm{\mu g} / \mathrm{ml}$ allicin which was dissolved in DMSO; Allicin-M - the cells were treated with $25 \mu \mathrm{g} / \mathrm{ml}$ allicin which was dissolved in DMSO; Allicin-M - the cells were treated with $50 \mu \mathrm{g} / \mathrm{ml}$ allicin which was dissolved in DMSO. A - Allicin effect on wound healing rate of different groups by wound healing assay in 5637 cell line (100x)

${ }^{*} p<0.05 ;{ }^{* *} p<0.01 ;{ }^{* * *} p<0.001$, compared with NC group; ${ }^{*} p<0.05$; ${ }^{* \#} p<0.01$, compared with Allicin-L group; ${ }^{s} p<0.05$, compared with Allicin-M. 
B

NC
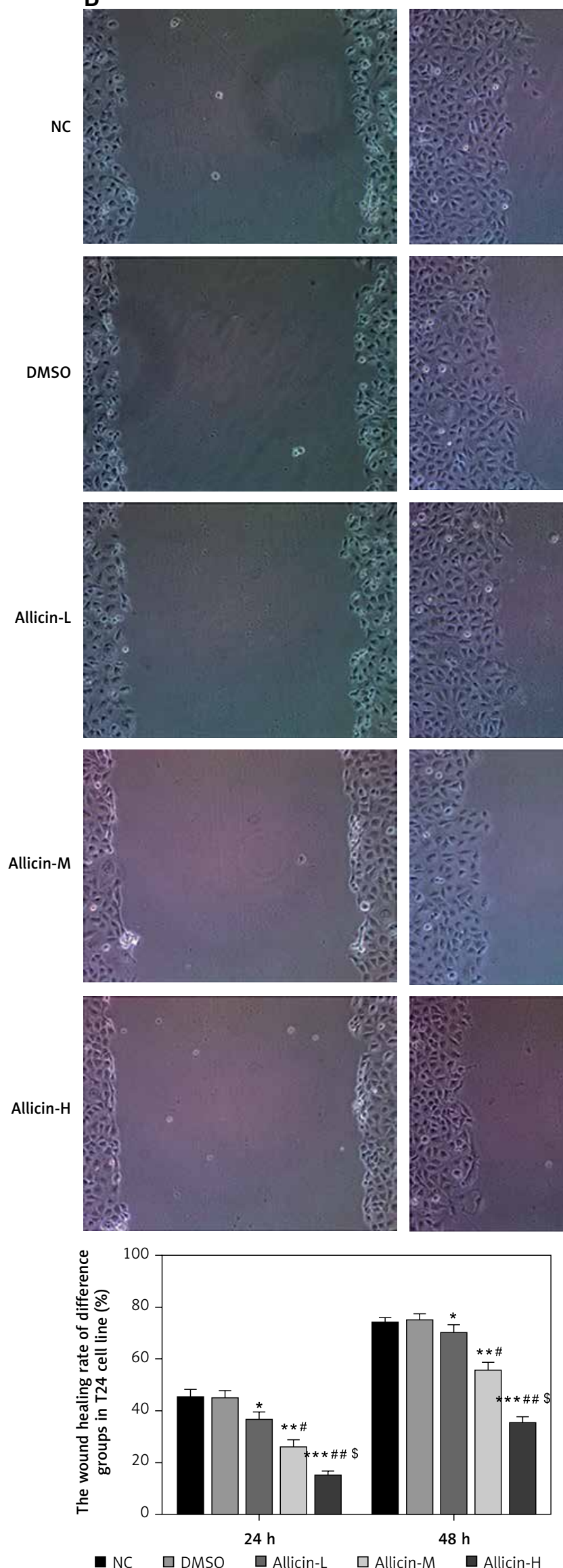

$24 \mathrm{~h}$
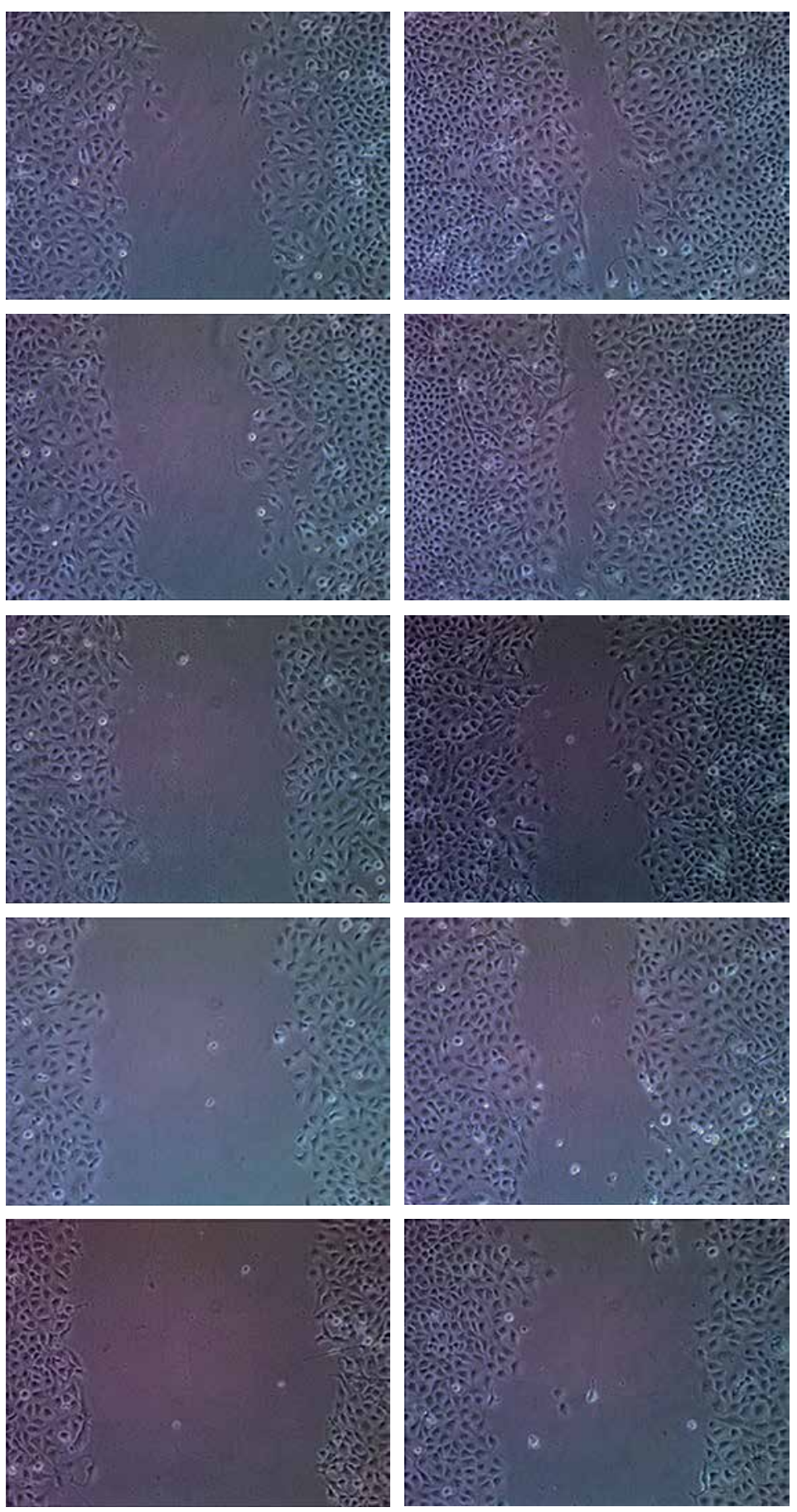

Figure 4. Cont. B - Allicin effect on wound healing rate of different groups by wound healing assay in T24 cell line $(100 x)$

${ }^{*} p<0.05 ;{ }^{* *} p<0.01 ;{ }^{* * *} p<0.001$, compared with NC group; ${ }^{\#} p<0.05 ;{ }^{\#} p<0.01$, compared with Allicin-L group; ${ }^{s} p<0.05$, compared with Allicin-M. 
A

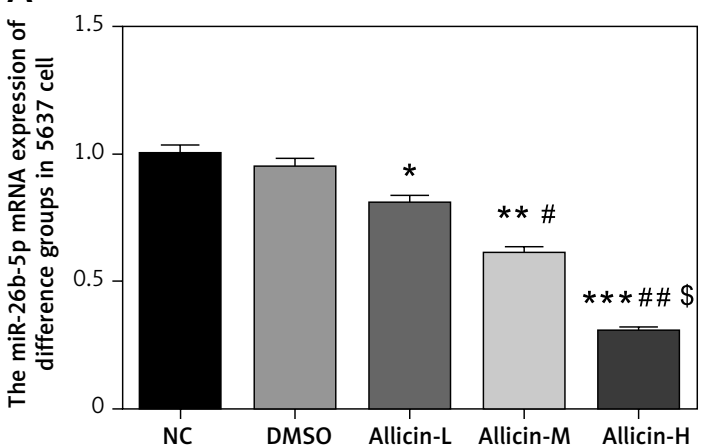

B

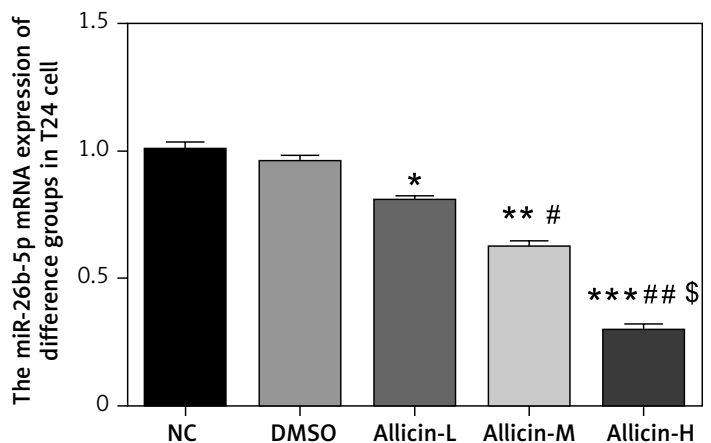

Figure 5. Allicin effect on miR-26b-5p mRNA expression in different groups by qRT-PCR assay. NC - The cells were treated with normal treatment; DMSO - the cells were treated with DMSO; Allicin-L - the cells were treated with $12.5 \mu \mathrm{g} / \mathrm{ml}$ allicin which was dissolved in DMSO; Allicin-M - the cells were treated with $25 \mu \mathrm{g} / \mathrm{ml}$ allicin which was dissolved in DMSO; Allicin-M - the cells were treated with $50 \mu \mathrm{g} / \mathrm{ml}$ allicin which was dissolved in DMSO. A - Allicin effect on miR-26b-5p mRNA expression in different groups by qRT-PCR assay in 5637 cell line. B - Allicin effect on miR-26b-5p mRNA expression in different groups by qRT-PCR assay in T24 cell line

${ }^{*} P<0.05 ;{ }^{* *} p<0.01 ;{ }^{* *} p<0.001$, compared with NC group; ${ }^{\#} p<0.05 ;{ }^{\# *} p<0.01$, compared with Allicin-L group; ${ }^{s} p<0.05$, compared with Allicin-M.

and miR-608 [24], decreases significantly in bladder cancer tissues, which could significantly inhibit the growth or metastasis of bladder cancer cells. Meanwhile, the expression of other miRNAs, such as miR-556-3p [25] and miR-495 [26], clearly increased, which could promote the metastasis and proliferation of bladder cancer cells remarkably. In this study, the experimental results showed that the expression level of miR-26b-5p was clearly decreased after allicin treatment. Therefore, it was speculated in our study that Allicin-mediated inhibition of bladder cancer activity might be intimately related to the decrease in miR-26b-5p.

$\mathrm{P} 13 \mathrm{~K} / \mathrm{AKT}$ signalling is imbalanced in multiple human tumours. Activated by P13K phosphorylation, AKT can promote cell proliferation, invasion and migration and inhibit cell apoptosis, which is the core effect of the proposed signalling pathway [27]. PTEN is an essential tumour suppressor gene, which can regulate the P13K/AKT signalling pathway by negative feedback. The loss of PTEN expression can cause tumour progression, poor prognosis and lymph node metastasis [28]. Furthermore, PTEN can dephosphorylate P13K and lose the activation capability of AKT, thus inhibiting the activity of P13K/AKT. Therefore, it is named the PTEN/PI3K/AKT signalling pathway by most researchers [29]. In the present study, allicin treatment significantly inhibited the expression of PTEN protein and the downstream $\mathrm{PI3K} / \mathrm{AKT}$ signalling pathway activity while inhibiting the expression of miR-26b-5p. Moreover, the dual luciferase reporter assay was used to verify the correlation between miR-26b-5p and PTEN in bladder cancer 5367 and T24 cells. The results suggested that miR-26b-5p could target the expression of PTEN in bladder cancer 5367 and T24 cells.
In conclusion, allicin can effectively inhibit the biological activity of bladder cancer cells by inhibiting the expression of miR-26b-5p/PTEN effectively.

\section{Conflict of interest}

The authors declare no conflict of interest. 

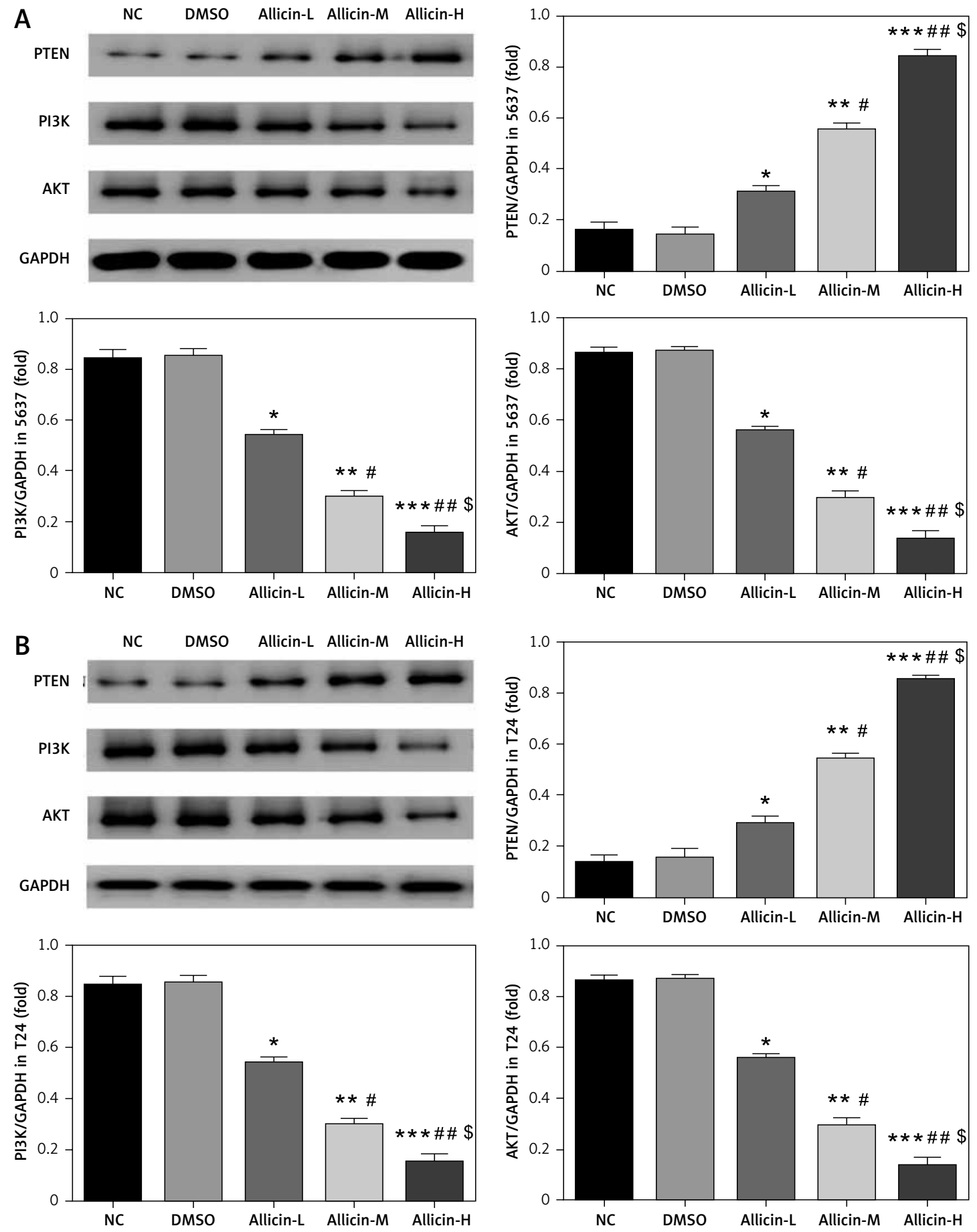

Figure 6. Allicin effect on relative protein expression by WB assay. NC - the cells were treated with normal treatment; DMSO - the cells were treated with DMSO; Allicin-L - the cells were treated with $12.5 \mathrm{\mu g} / \mathrm{ml}$ allicin which was dissolved in DMSO; Allicin-M - the cells were treated with $25 \mathrm{\mu g} / \mathrm{ml}$ allicin which was dissolved in DMSO; Allicin-M - the cells were treated with $50 \mu \mathrm{g} / \mathrm{ml}$ allicin which was dissolved in DMSO. A - Allicin effect on relative protein expression by WB assay in 5637 cell line. B - Allicin effect on relative protein expression by WB assay in T24 cell line

${ }^{*} P<0.05 ;{ }^{* *} p<0.01 ;{ }^{* * *} p<0.001$, compared with NC group; ${ }^{*} p<0.05 ;{ }^{* \#} p<0.01$, compared with Allicin-L group; ${ }^{s} p<0.05$, compared with Allicin-M. 
A

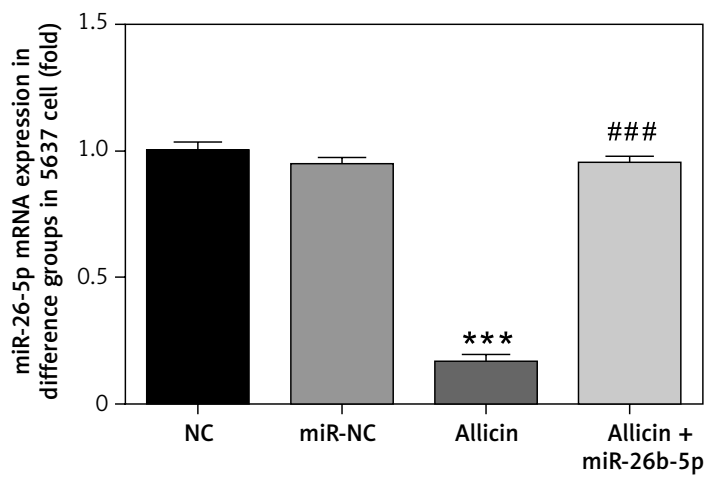

\section{B}

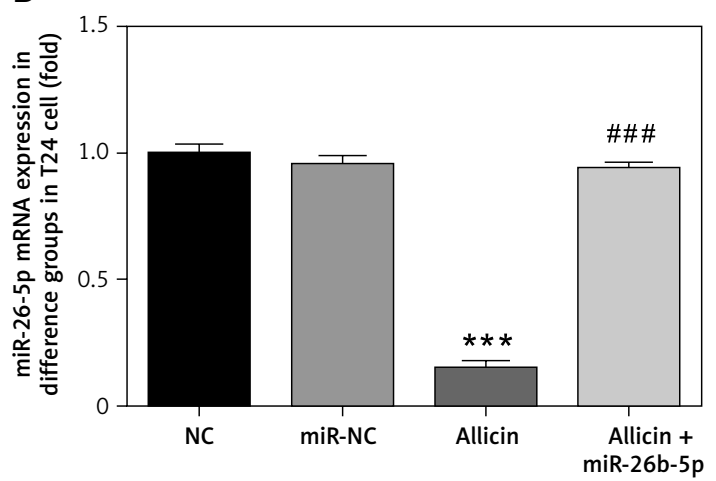

Figure 7. miR-26-5p mRNA expression in different groups. NC - the cells were treated with normal treatment; miR-NC - the cells were transfected with miR-negative control (NC); allicin - the cells were treated with $50 \mu \mathrm{g} / \mathrm{ml}$ allicin; allicin + miR-26b-5p - The cells were transfected with miR-26b-5p and treated with $50 \mu \mathrm{g} / \mathrm{ml}$ allicin. A - miR-26-5p mRNA expression in different groups in 5637 cell line. B - miR-26-5p mRNA expression in different groups in T24 cell line

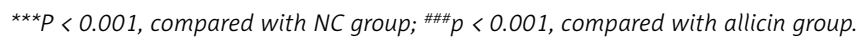

A

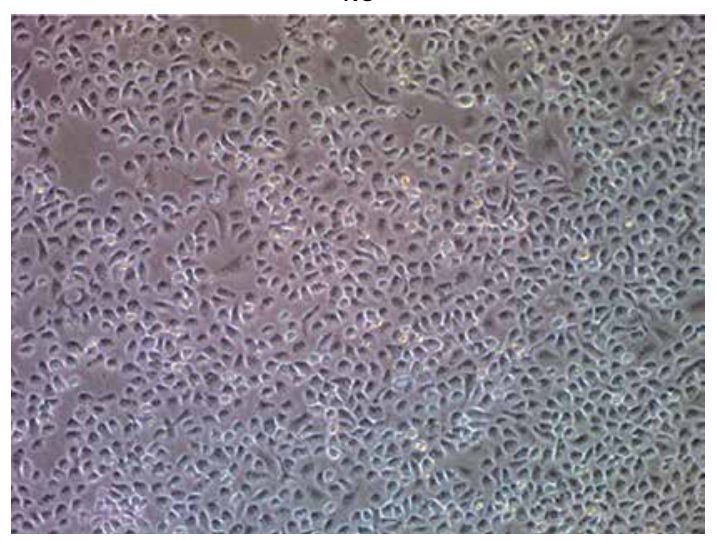

Allicin
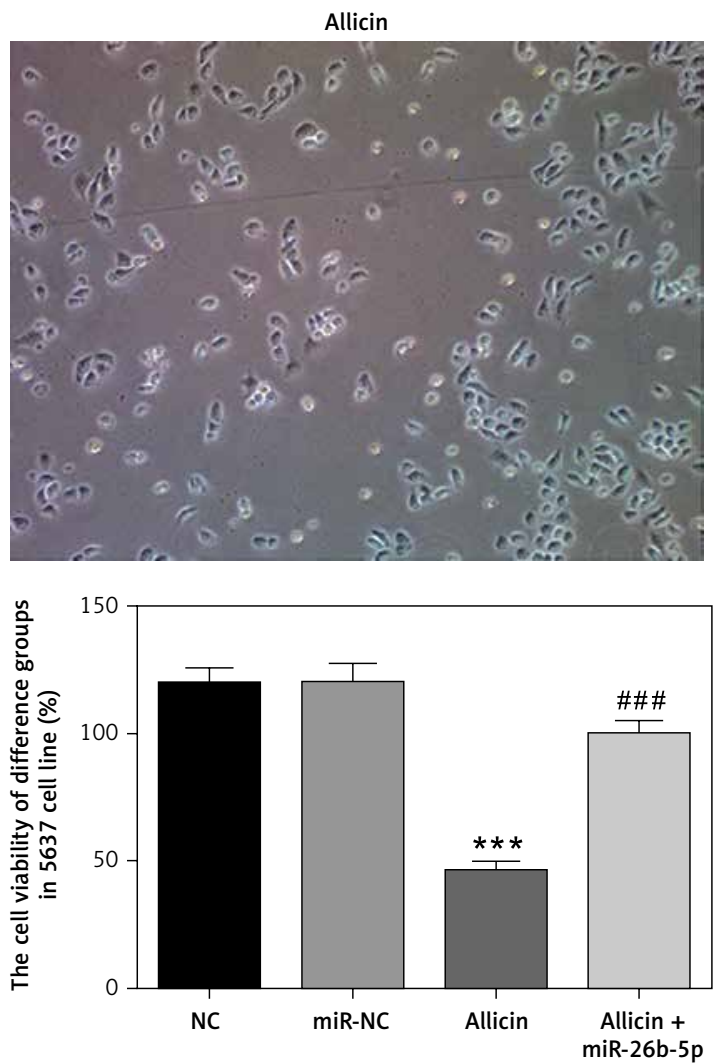

miR-NC

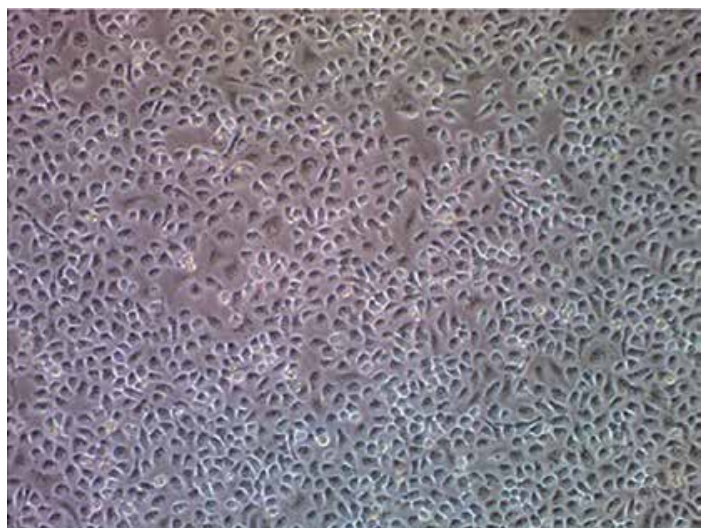

Allicin + miR-26b-5p

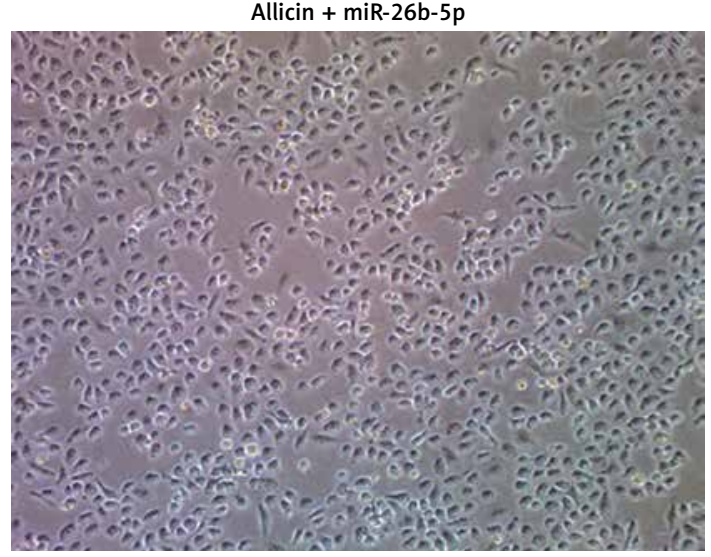

Figure 8. The cell proliferation rate of different groups by MTT assay (100x). NC - the cells were treated with normal treatment; miR-NC - the cells were transfected with miR-negative control (NC); Allicin - the cells were treated with $50 \mu \mathrm{g} / \mathrm{ml} \mathrm{al-}$ licin; allicin + miR-26b-5p - The cells were transfected with miR-26b-5p and treated with $50 \mu \mathrm{g} / \mathrm{ml}$ allicin. A - The cell proliferation rate of different groups by MTT assay in 5637 cell lines (100x)

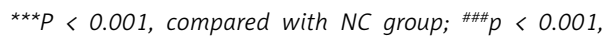
compared with allicin group. 
B

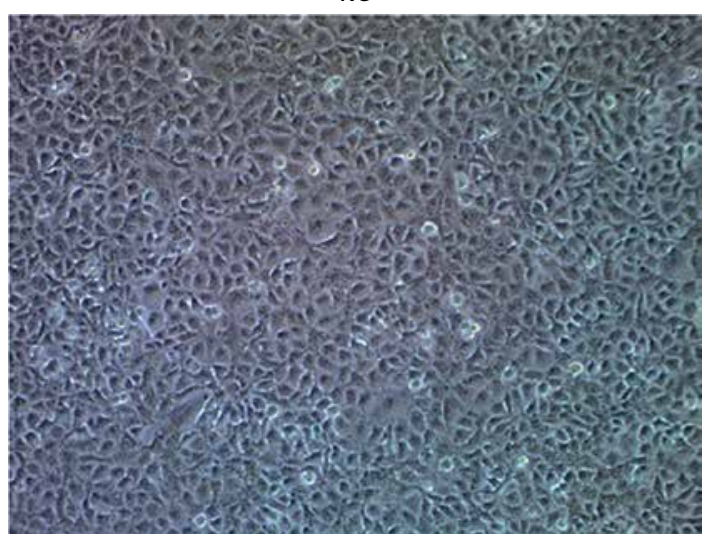

Allicin
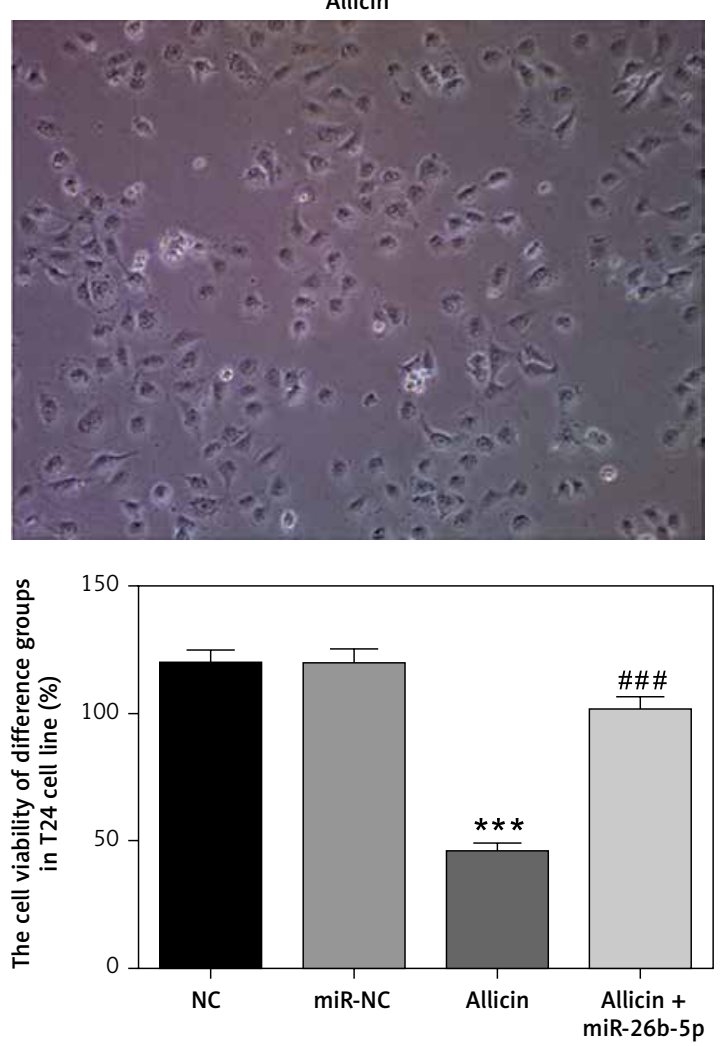

miR-NC

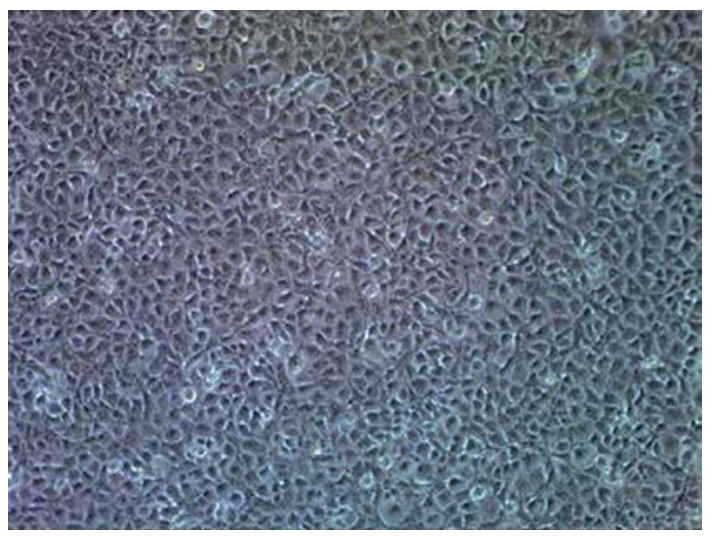

Allicin + miR-26b-5p

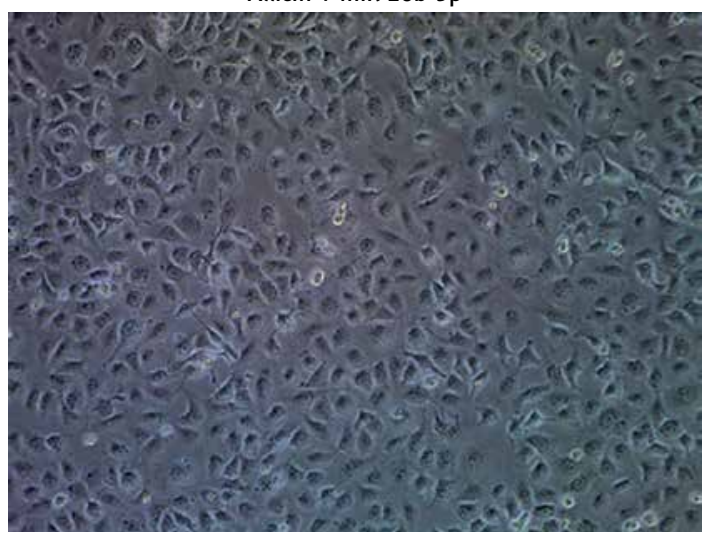

Figure 8. Cont. B - The cell proliferation rate of different groups by MTT assay in T24 cell lines (100x) ${ }^{* * *} P<0.001$, compared with NC group; \#\#\# $p<0.001$ compared with allicin group. 
A

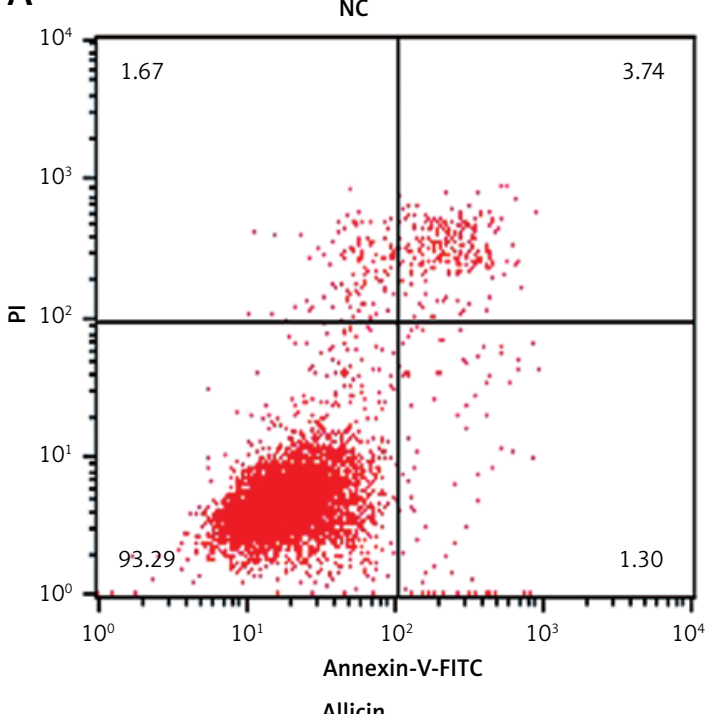

Allicin
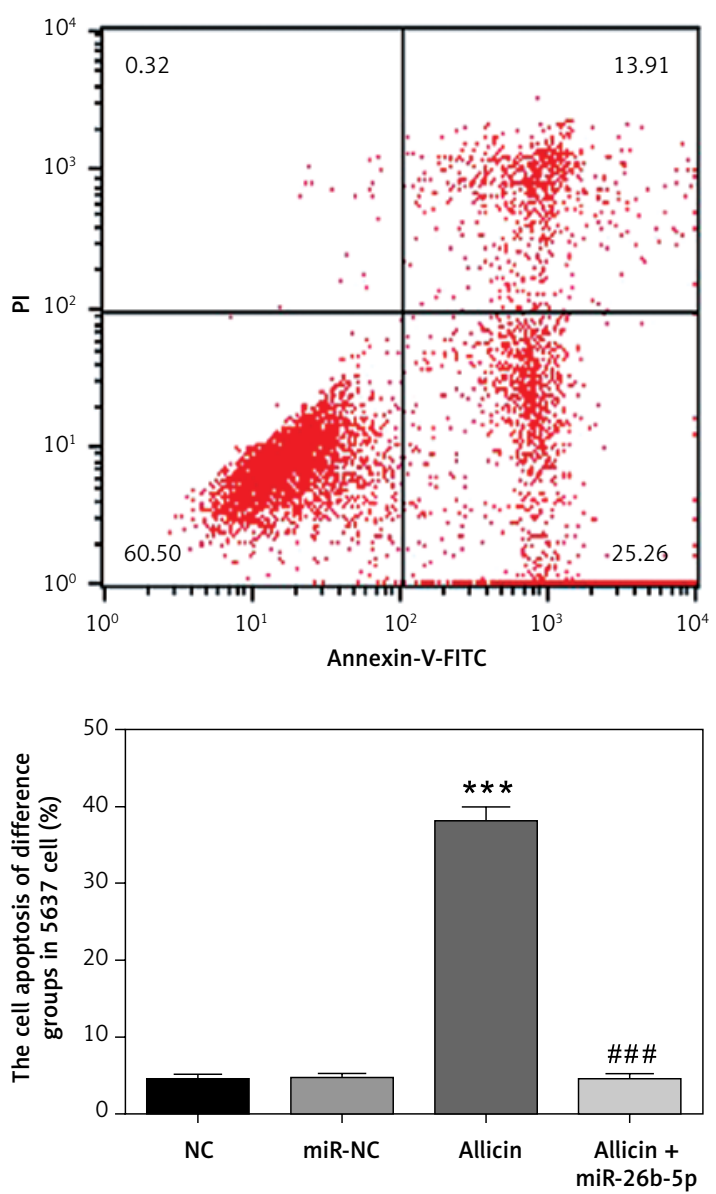

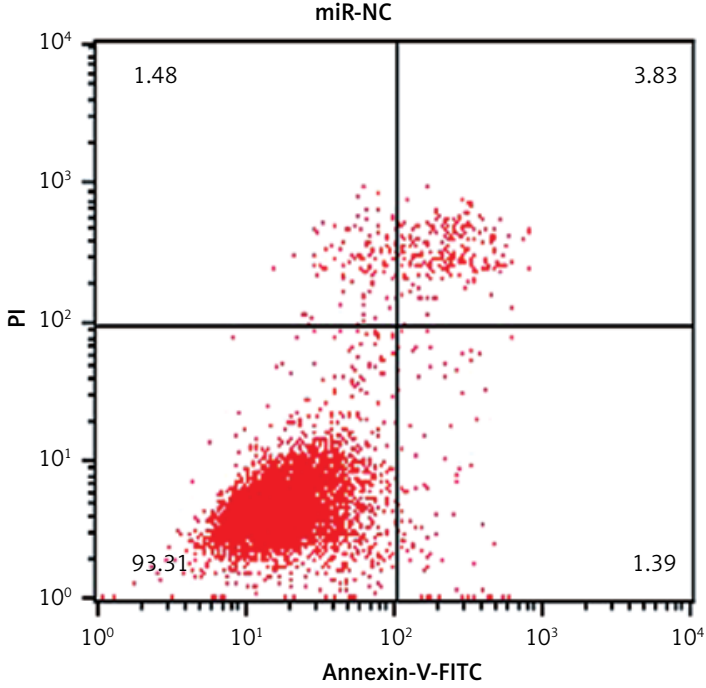

Allicin + miR-26b-5p

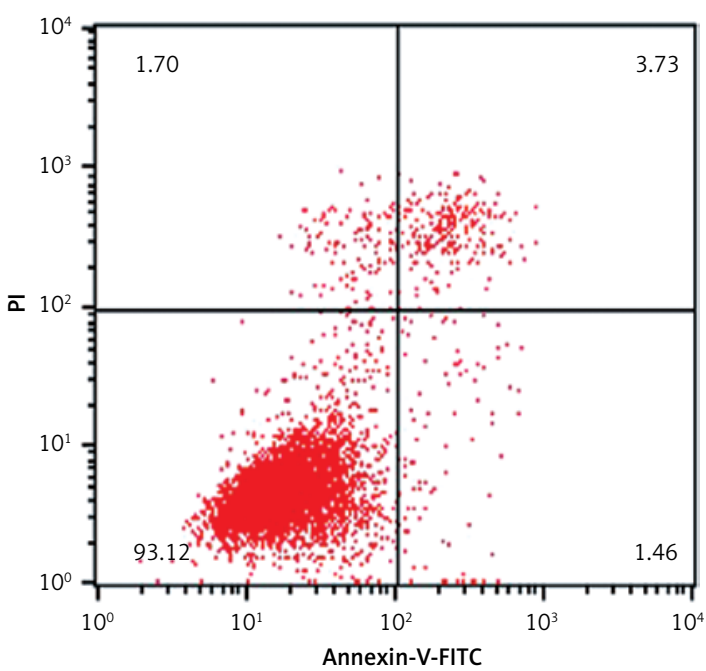

Figure 9. The cell apoptosis rate of different groups by flow cytometry. NC - the cells were treated with normal treatment; miR-NC - the cells were transfected with miR-negative control (NC); Allicin - the cells were treated with $50 \mu \mathrm{g} / \mathrm{ml}$ allicin; allicin + miR-26b-5p - the cells were transfected with miR$26 \mathrm{~b}-5 \mathrm{p}$ and treated with $50 \mu \mathrm{g} / \mathrm{ml}$ allicin. A - The cell apoptosis rate of different groups by flow cytometry in 5637 cell line

${ }^{* *} P<0.001$, compared with NC group; ${ }^{\# \#} p<0.001$, compared with allicin group. 
B

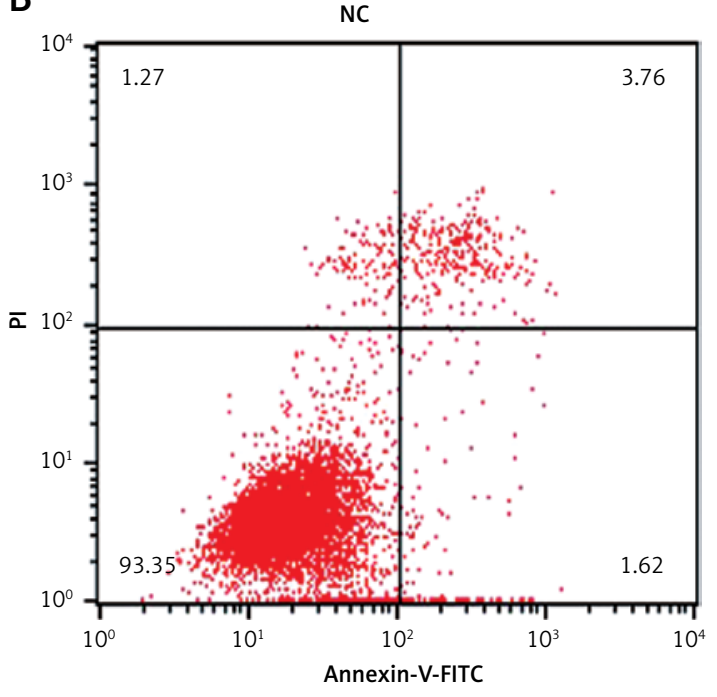

Allicin
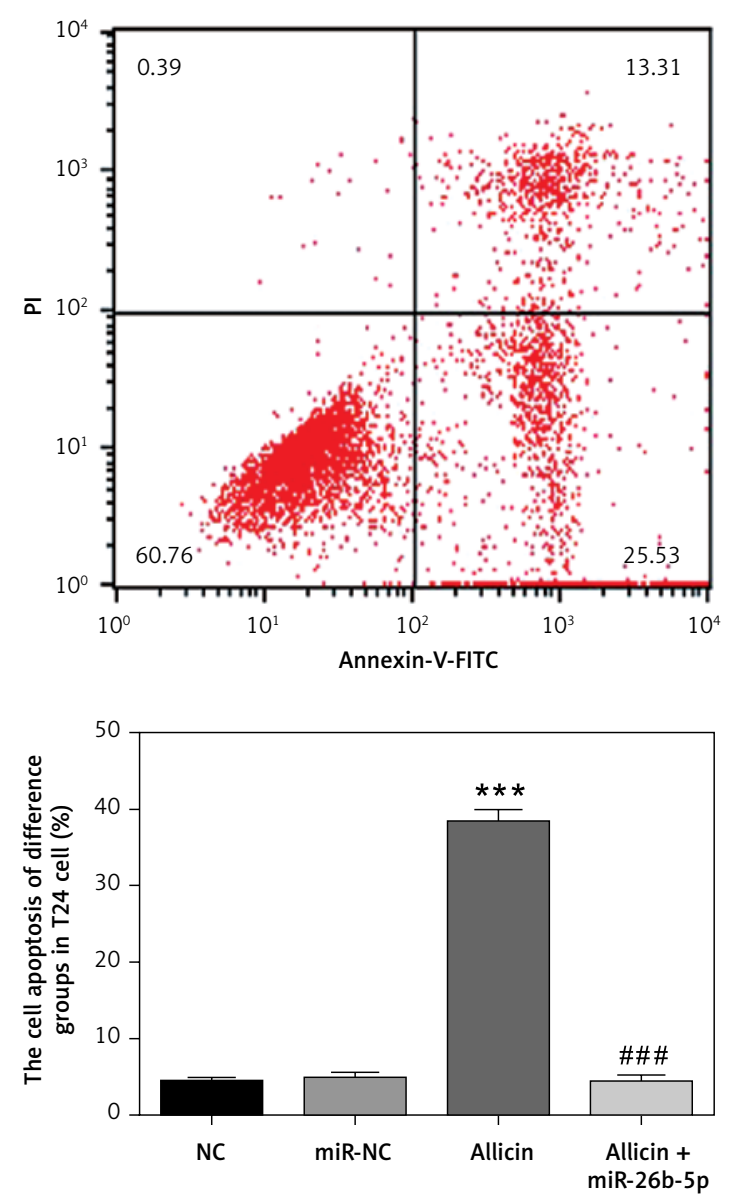

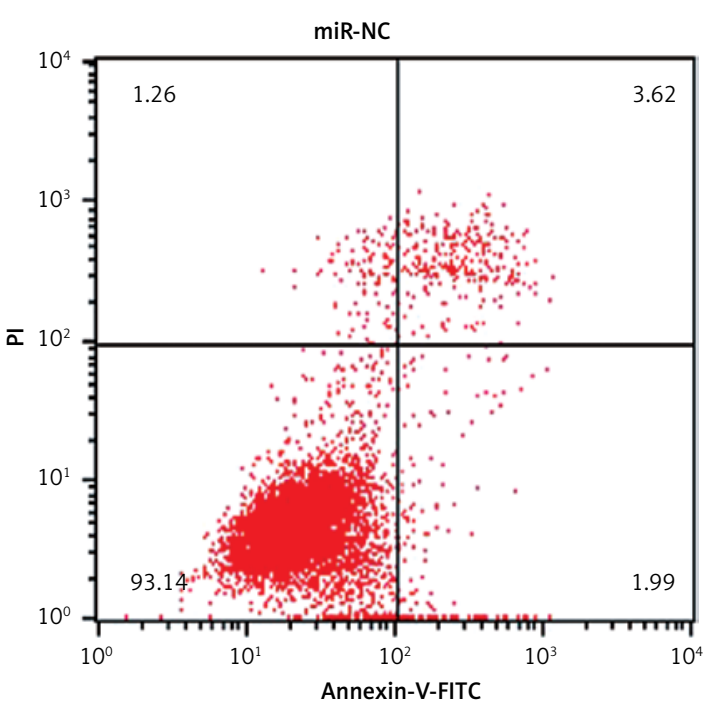

Allicin + miR-26b-5p

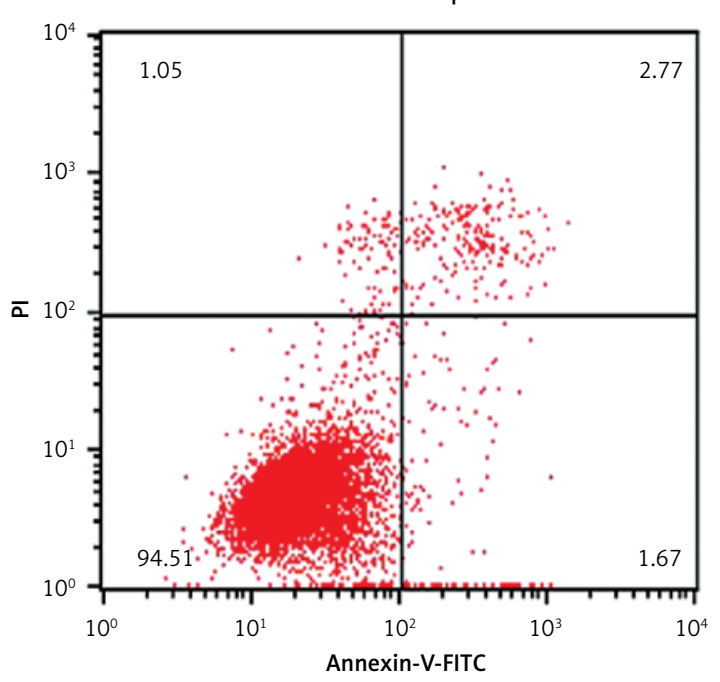

Figure 9. Cont. B - The cell apoptosis rate of different groups by flow cytometry in T24 cell line

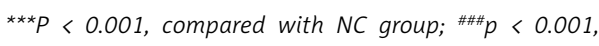
compared with allicin group. 
A
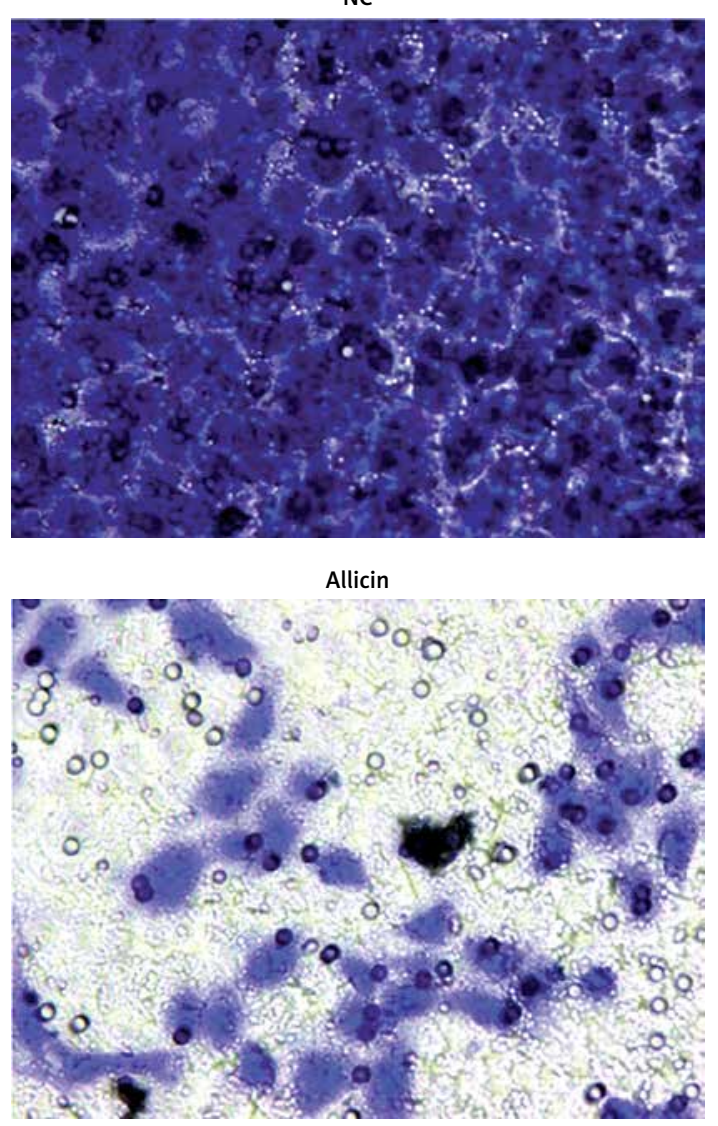

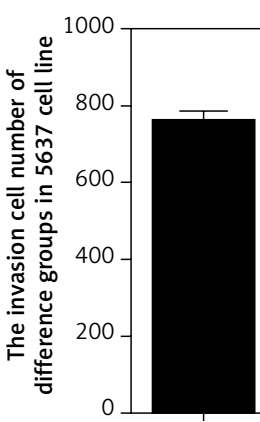

NC

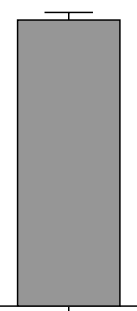

miR-NC

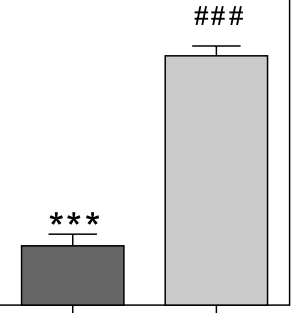

Allicin

Allicin + miR-26b-5p

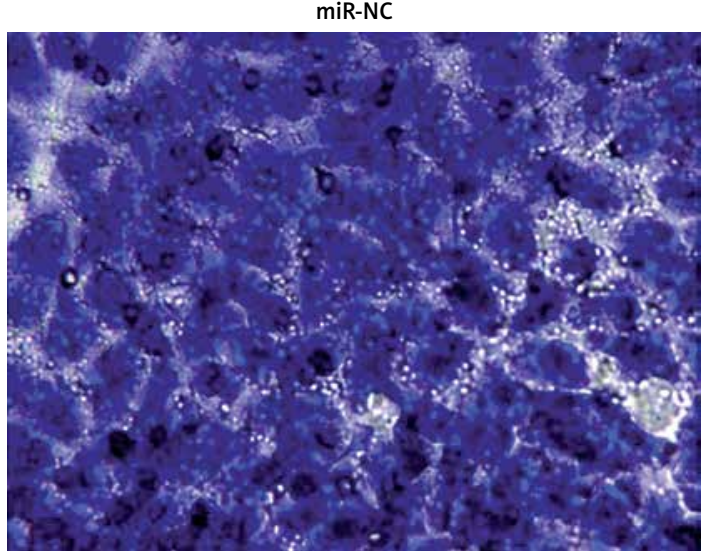

Allicin + miR-26b-5p

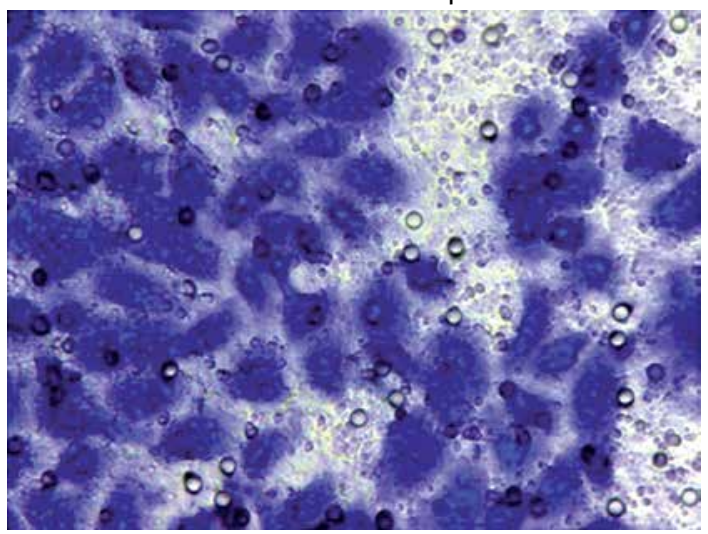

Figure 10. The invasion cell number of different groups by transwell assay (200x). NC - the cells were treated with normal treatment; miR-NC - the cells were transfected with miR-negative control (NC); Allicin - the cells were treated with $50 \mu \mathrm{g} / \mathrm{ml}$ allicin; allicin + miR-26b-5p - the cells were transfected with miR-26b-5p and treated with $50 \mu \mathrm{g} / \mathrm{ml}$ allicin. A - The invasion 5637 cell number of different groups by transwell assay (200x)

${ }^{* * *} P<0.001$, compared with NC group; ${ }^{\# \#} p<0.001$, compared with allicin group. 
B
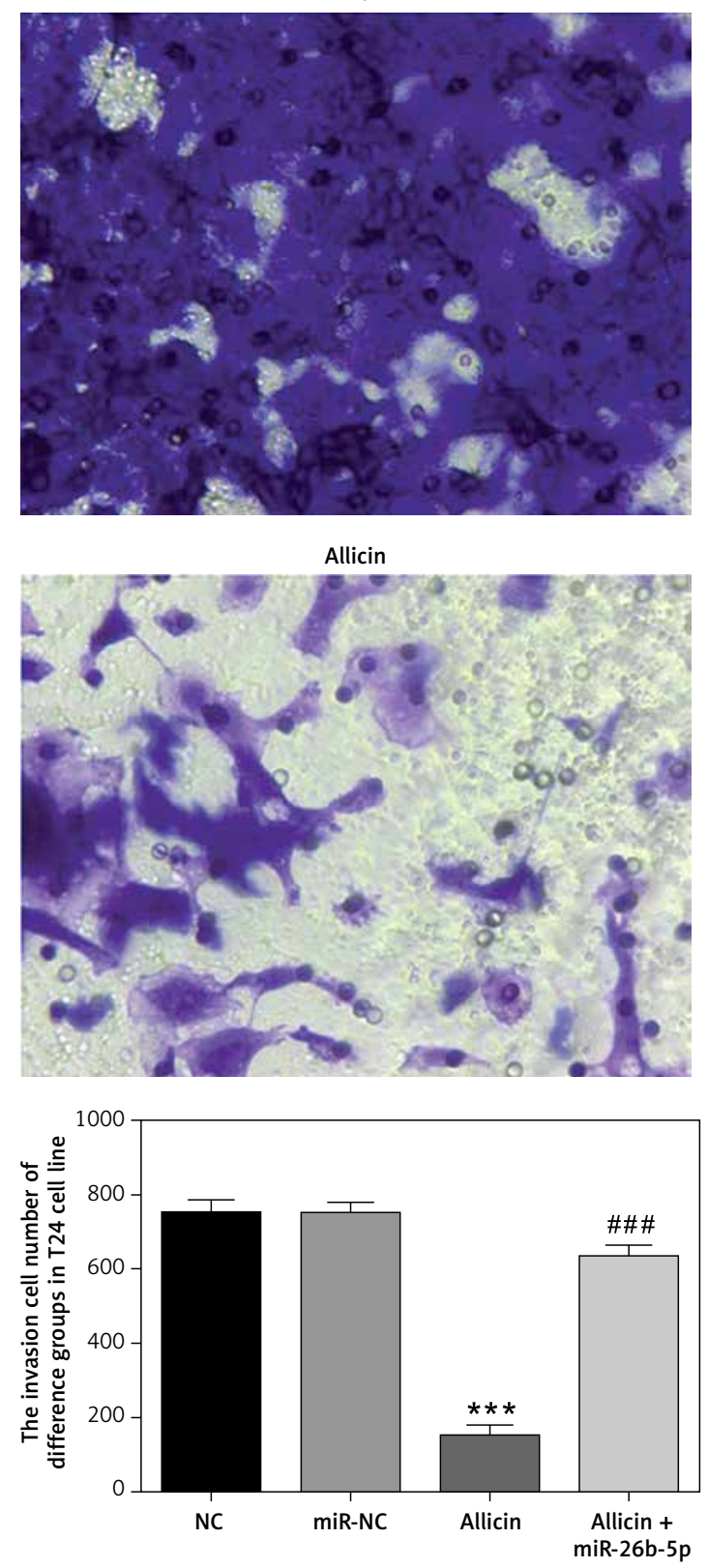

miR-NC
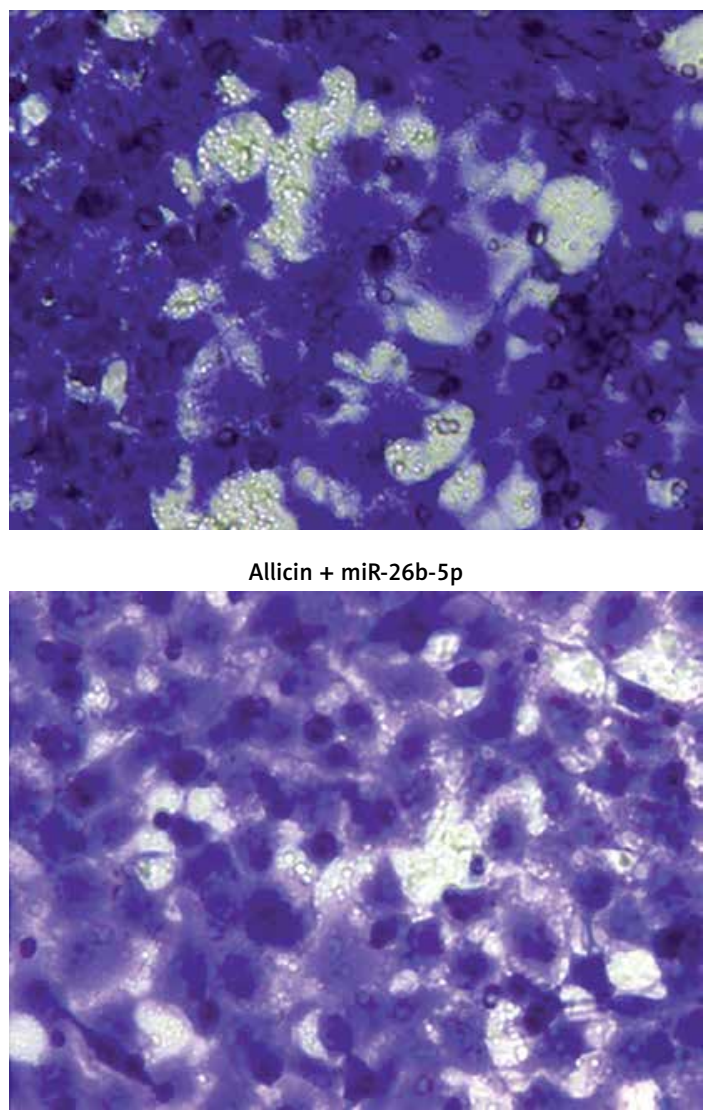

Figure 10. Cont. B - The invasion T24 cell number of different groups by transwell assay (200x) ${ }^{* * *} P<0.001$, compared with NC group; ${ }^{\# \#} p<0.001$, compared with allicin group. 

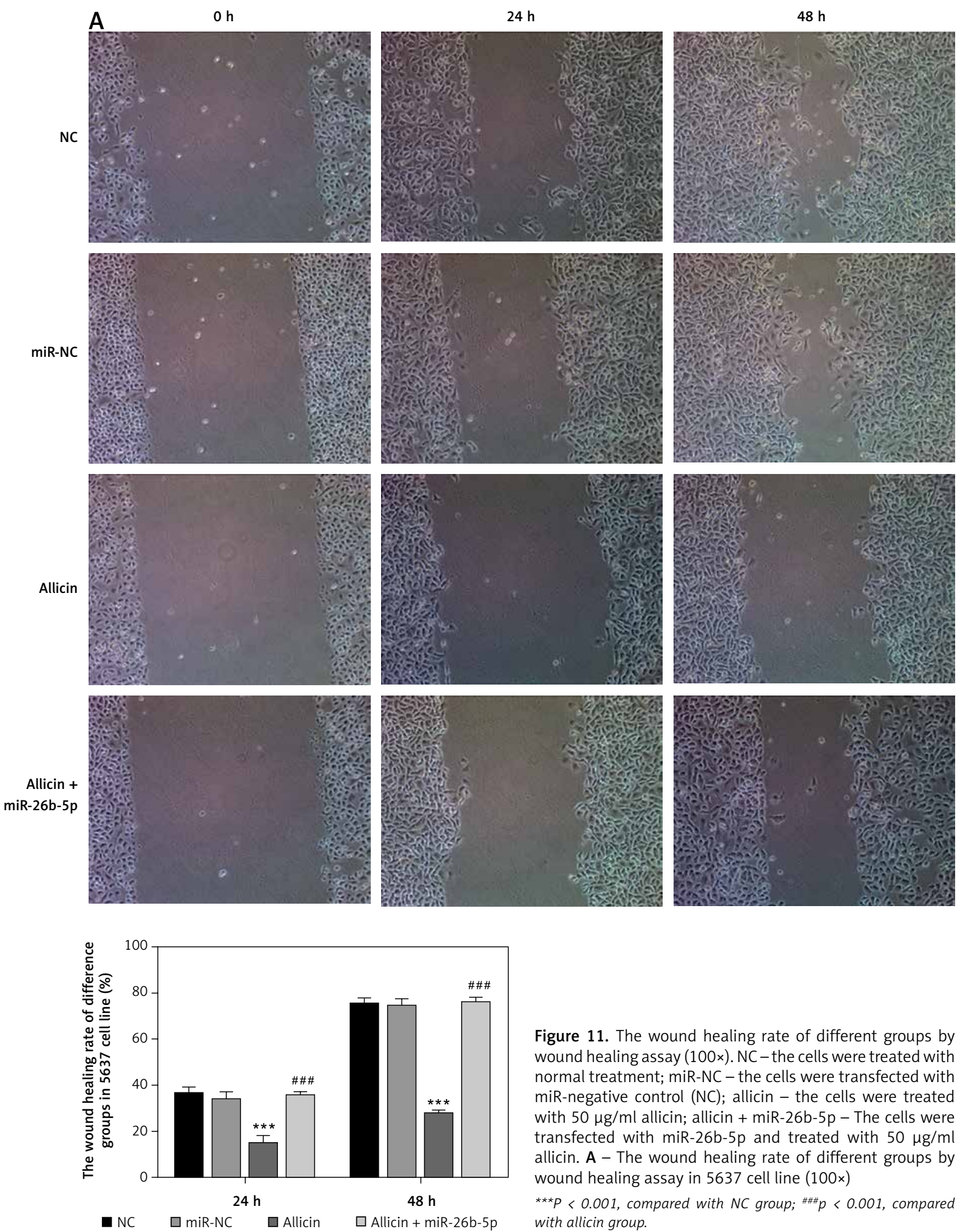

Figure 11. The wound healing rate of different groups by wound healing assay (100x). NC - the cells were treated with normal treatment; miR-NC - the cells were transfected with miR-negative control (NC); allicin - the cells were treated with $50 \mu \mathrm{g} / \mathrm{ml}$ allicin; allicin + miR-26b-5p - The cells were transfected with miR-26b-5p and treated with $50 \mu \mathrm{g} / \mathrm{ml}$ allicin. A - The wound healing rate of different groups by wound healing assay in 5637 cell line (100x)

${ }^{* * *} P<0.001$, compared with NC group; ${ }^{\# \# p} p<0.001$, compared with allicin group. 


\section{B}

NC
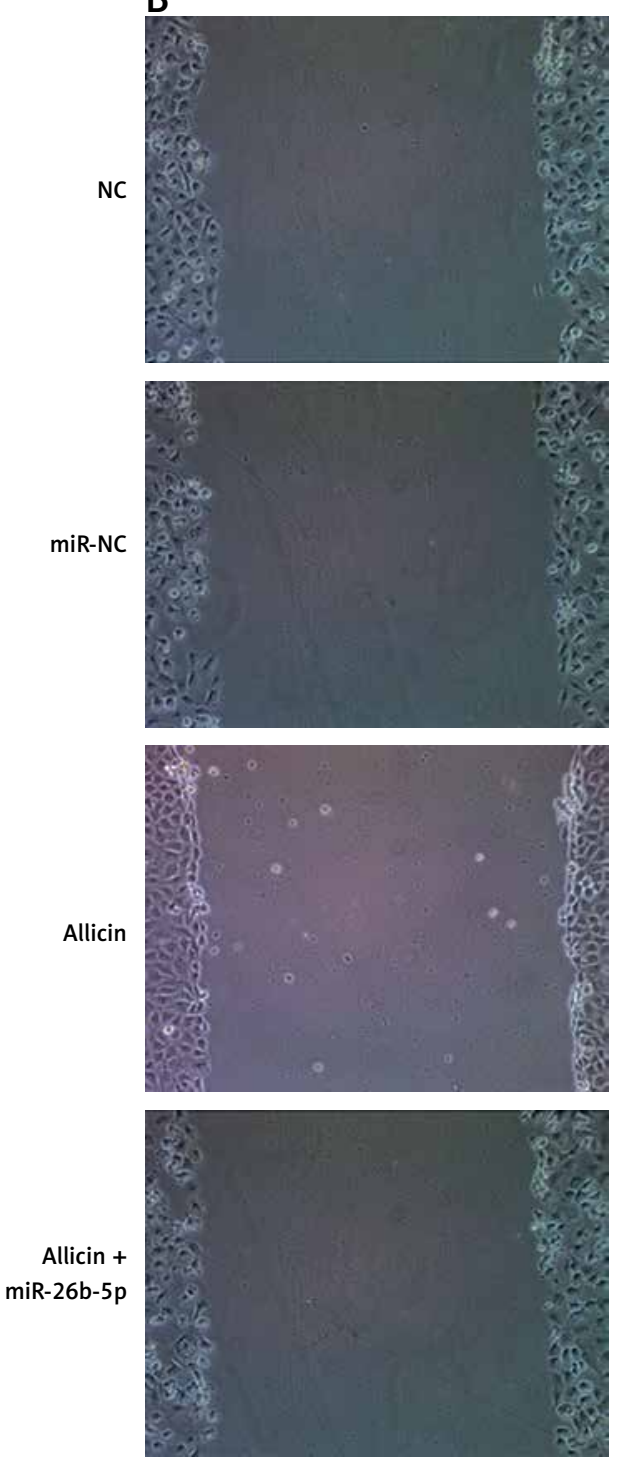

$24 \mathrm{~h}$
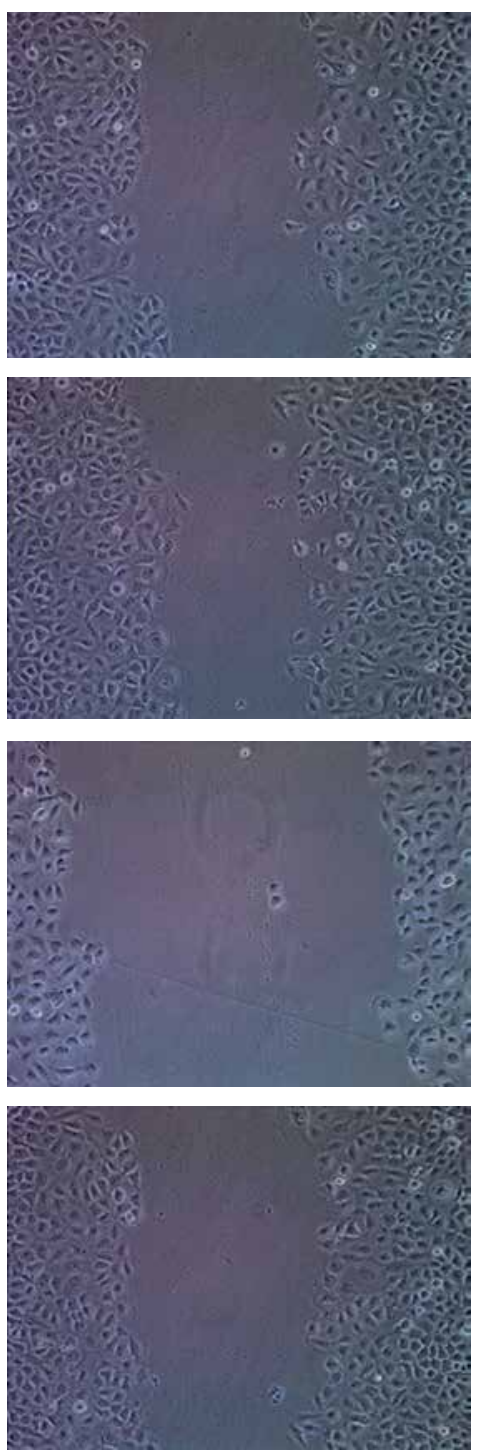

$48 \mathrm{~h}$
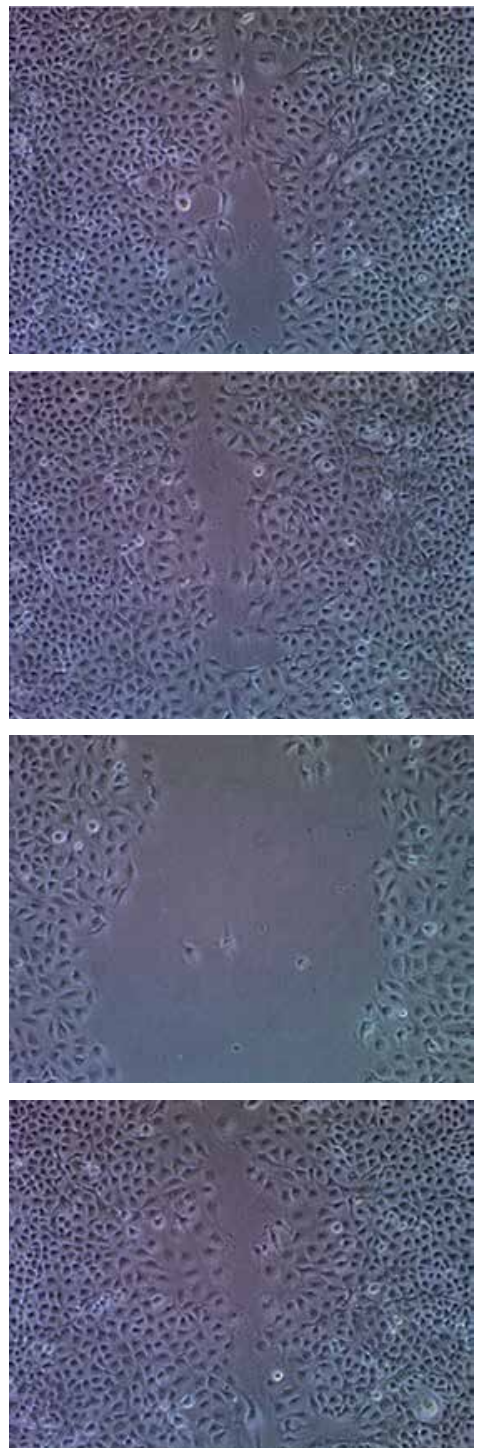

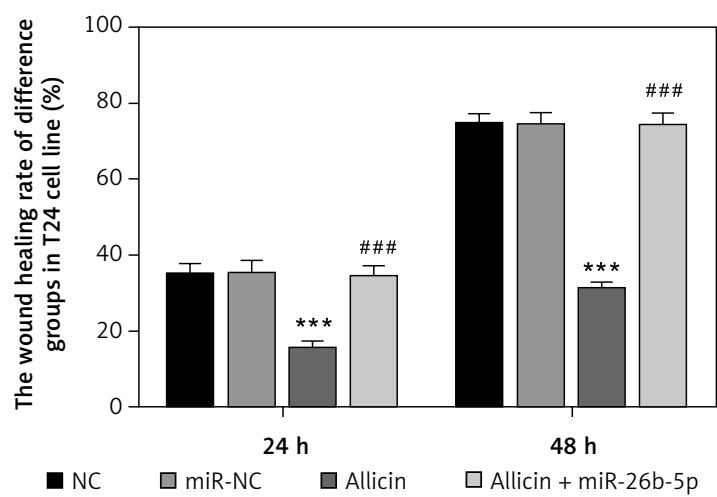

Figure 11. Cont. B - The wound healing rate of different groups by wound healing assay in T24 cell line (100x)

${ }^{* * *} P<0.001$, compared with NC group; ${ }^{\# \# p}<<0.001$, compared with allicin group. 

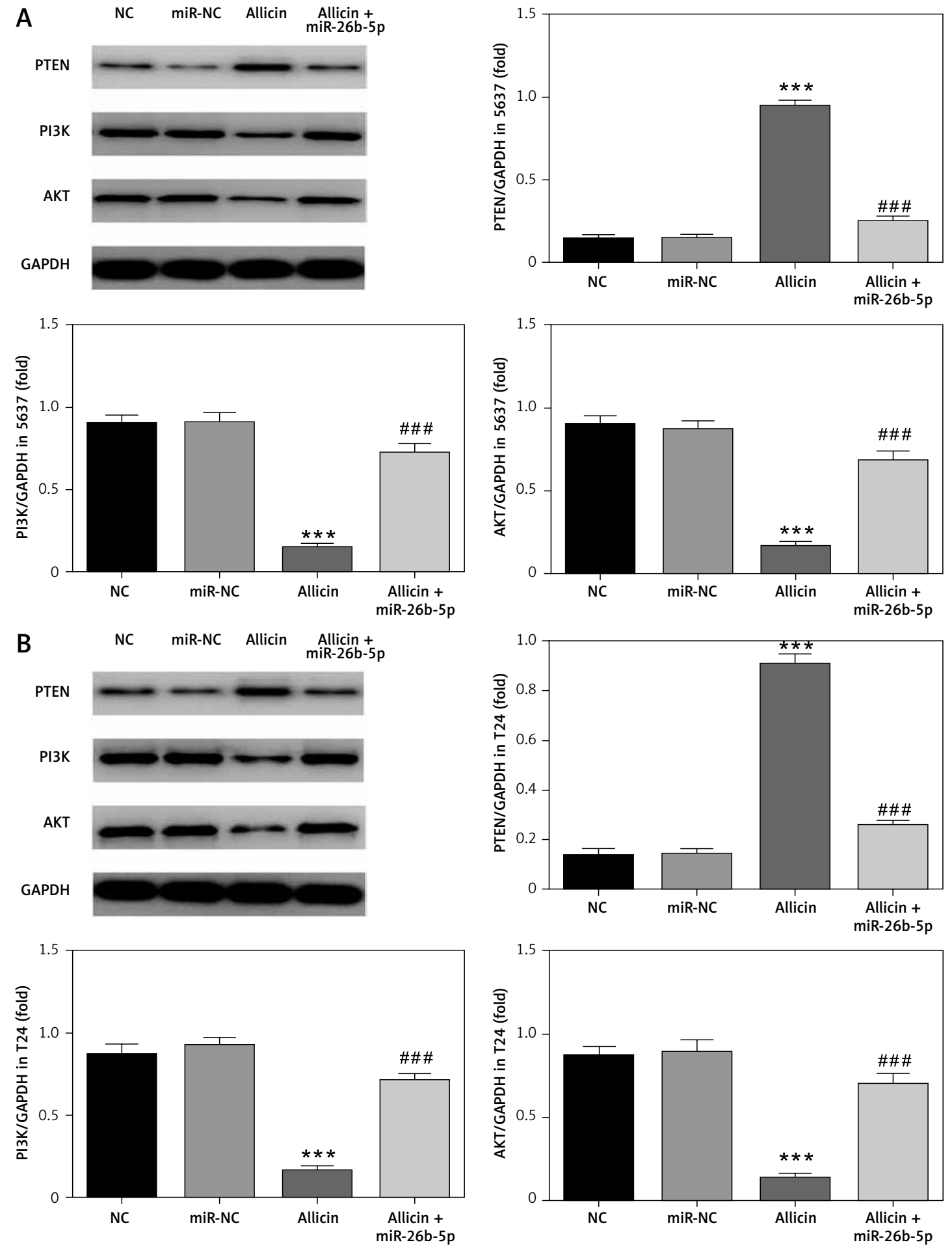

Figure 12. The relative protein expression by WB assay. NC - The cells were treated with normal treatment; miR-NC - the cells were transfected with miR-negative control (NC); Allicin - the cells were treated with $50 \mu \mathrm{g} / \mathrm{ml}$ allicin; allicin + miR-26b-5p - the cells were transfected with miR-26b-5p and treated with $50 \mu \mathrm{g} / \mathrm{ml}$ allicin. A - The relative protein expression by WB assay in 5637 cell line. B - The relative protein expression by WB assay in T24 cell line

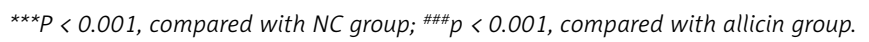


A Position 41-47 of PTEN 3'UTR $\quad$ 5' ...ACACCAUGAAAAUAAACUUGAAU... 7 mer-A1 $-0.23 \quad 95 \quad-0.23 \quad 6.860$ hsa-miR-26b-5p 3' UGGAUAGGACUUAAUGAACUU

\section{B}

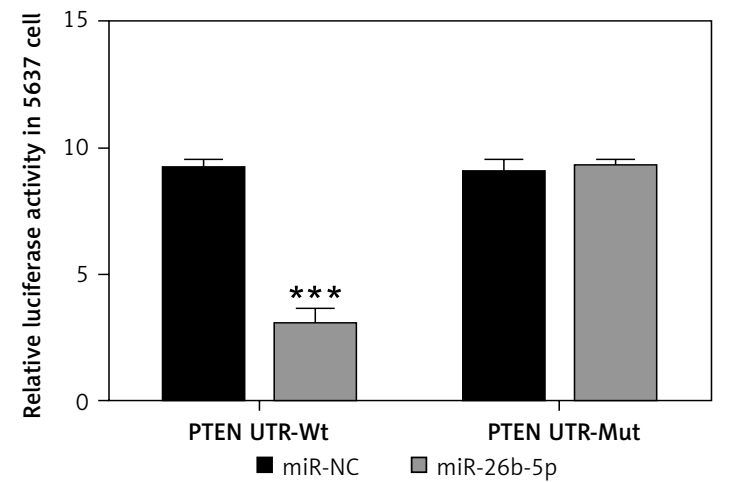

Position 41-47 of PTEN 3'UTR

5' ...ACACCAUGAAAAUAAACUUGAAU... 7mer-A1 -0.23

95

$-0.23 \quad 6.860$

hsa-miR-26b-5p

3' UGGAUAGGACUUAAUGAACUU

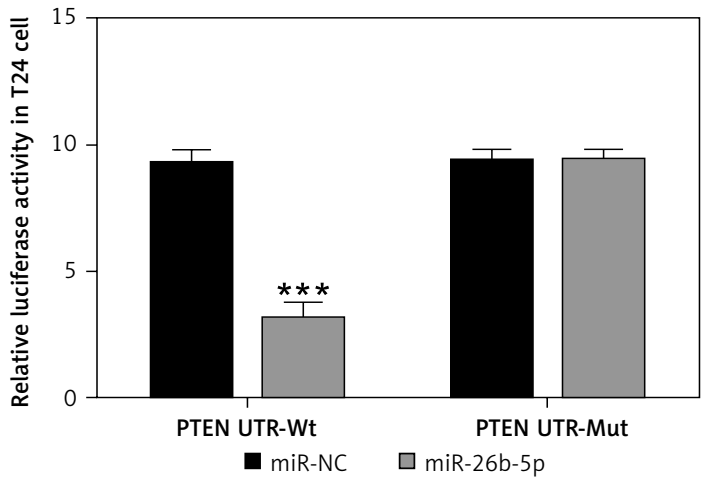

Figure 13. The correlation between miR-26b-5p and PTEN by dual luciferase assay. NC - The cells were treated with normal treatment; miR-NC - The cells were transfected with miR-negative control (NC); Allicin - The cells were treated with $50 \mu \mathrm{g} / \mathrm{ml}$ allicin; allicin + miR-26b-5p - The cells were transfected with miR-26b-5p and treated with $50 \mu \mathrm{g} / \mathrm{ml}$ allicin. A - The correlation between miR-26b-5p and PTEN by dual luciferase assay in 5637 cell line. B - The correlation between miR-26b-5p and PTEN by dual luciferase assay in T24 cell line

${ }^{* * *} P<0.001$, compared with NC group; ${ }^{\# \# \# p} p<0.001$, compared with allicin group.

\section{References}

1. He YT, Li DJ, Liang D, et al. Incidence and mortality of bladder cancer in China, 2014. Zhonghua Zhong Liu Za Zhi 2018; 40: 647-52.

2. Chen W, Sun K, Zheng R, et al. Cancer incidence and mortality in China, 2014. Chin J Cancer Res 2018; 30: 1-12.

3. Bray F, Ferlay J, Soerjomataram I, Siegel RL, Torre LA, Jemal A. Global cancer statistics 2018: GLOBOCAN estimates of incidence and mortality worldwide for 36 cancers in 185 countries. CA Cancer J Clin 2018; 68: 394-424.

4. Voltaggio L, Cimino-Mathews A, Bishop JA, et al. Current concepts in the diagnosis and pathobiology of intraepithelial neoplasia: a review by organ system. CA Cancer J Clin 2016; 66: 408-36.

5. Niu Q, Lu Y, Xu S, et al. Clinicopathological characteristics and survival outcomes of bladder neuroendocrine carcinomas: a population-based study. Cancer Manag Res 2018; 10: 4479-89.

6. Zhang $\mathrm{Q}$, Yang D. Allicin suppresses the migration and invasion in cervical cancer cells mainly by inhibiting NRF2. Exp Ther Med 2019; 17: 1523-8.
7. Chu Q, Ling MT, Feng $\mathrm{H}$, et al. A novel anticancer effect of garlic derivatives: inhibition of cancer cell invasion through restoration of E-cadherin expression. Carcinogenesis 2006; 27: 2180-9.

8. Oommen S, Anto RJ, Srinivas G, Karunagaran D. Allicin (from garlic) induces caspase-mediated apoptosis in cancer cells. Eur J Pharmacol 2004; 485: 97-103.

9. Borlinghaus J, Albrecht F, Gruhlke MC, Nwachukwu ID, Slusarenko AJ. Allicin: chemistry and biological properties. Molecules 2014; 19: 12591-618.

10. Ilić DP, Stojanović S, Najman S, et al. Biological evaluation of synthesized allicin and its transformation products obtained by microwaves in methanol: antioxidant activity and effect on cell growth. Biotechnol Biotechnol Equip 2015; 29: 189-94.

11. El-Sheakh AR, Ghoneim HA, Suddek GM, Ammar ESM. Attenuation of oxidative stress, inflammation, and endothelial dysfunction in hypercholesterolemic rabbits by allicin. Can J Physiol Pharmacol 2016; 94: 216-24.

12. Liu H, Mao P, Wang J, Wang T, Xie CH. Allicin protects PC12 cells against 6 -OHDA-induced oxidative stress and mitochondrial dysfunction via regulating mitochondrial dynamics. Cell Physiol Biochem 2015; 36: 966-79. 
13. Li C, Lun W, Zhao X, et al. Allicin alleviates inflammation of trinitrobenzenesulfonic acid-induced rats and suppresses P38 and JNK pathways in Caco-2 cells. Mediators Inflamm 2015; 2015: 434692.

14. Zou X, Liang J, Sun J, et al. Allicin sensitizes hepatocellular cancer cells to anti-tumor activity of 5-fluorouracil through ROS-mediated mitochondrial pathway. J Pharmacol Sci 2016; 131: 233-40.

15. Luo R, Fang D, Hang H, Tang Z. The mechanism in gastric cancer chemoprevention by allicin. Anticancer Agents Med Chem 2016; 16: 802-9.

16. Xu L, Yu J, Zhai D, et al. Role of JNK activation and mitochondrial Bax translocation in allicin-induced apoptosis in human ovarian cancer SKOV3 cells. Evid Based Complement Alternat Med 2014; 2014: 378684.

17. Miron T, Wilchek M, Sharp A, et al. Allicin inhibits cell growth and induces apoptosis through the mitochondrial pathway in HL60 and U937 cells. J Nutr Biochem 2008; 19: 524-35.

18. Duan R, Zhang Z, Zheng F, et al. Combining protein and miRNA quantification for bladder cancer analysis. ACS Appl Mater Interfaces 2017; 9: 23420-7.

19. Mitash N, Tiwari S, Agnihotri S, Mandhani A. Bladder cancer: microRNAs as biomolecules for prognostication and surveillance. Indian J Urol 2017; 33: 127-33.

20. Blanca A, Cheng L, Montironi R, et al. Mirna expression in bladder cancer and their potential role in clinical practice. Curr Drug Metab 2017; 18: 712-22.

21. Guo J, Cao R, Yu X, Xiao Z, Chen Z. MicroRNA-223-3p inhibits human bladder cancer cell migration and invasion. Tumour Biol 2017; 39: 1010428317691678.

22. Wei Z, Hu X, Liu J, Zhu W, Zhan X, Sun S. MicroRNA-497 upregulation inhibits cell invasion and metastasis in T24 and BIU-87 bladder cancer cells. Mol Med Rep 2017; 16: 2055-60.

23. Luo H, Yang R, Li C, et al. MicroRNA-139-5p inhibits bladder cancer proliferation and self-renewal by targeting the Bmi1 oncogene. Tumour Biol 2017; 39: 1010428317718414

24. Liang Z, Wang X, Xu X, et al. MicroRNA-608 inhibits proliferation of bladder cancer via AKT /FOXO3a signaling pathway. Mol Cancer 2017; 16: 96.

25. Feng C, Sun P, Hu J, et al. miRNA-556-3p promotes human bladder cancer proliferation-migration and invasion by negatively regulating DAB2IP expression. Int J Oncol 2017; 50: 2101-12.

26. Tan M, Mu X, Liu Z, et al. microRNA-495 promotes bladder cancer cell growth and invasion by targeting phosphatase and tensin homolog. Biochem Biophys Res Commun 2017; 483: 867-73.

27. Feng X, Jiang J, Shi S, Xie H, Zhou L, Zheng S. Knockdown of miR-25 increases the sensitivity of liver cancer stem cells to TRAIL-induced apoptosis via PTEN/PI3K/Akt/Bad signaling pathway. Int J Oncol 2016; 49: 2600-10.

28. Wu YR, Qi HJ, Deng DF, Luo YY, Yang SL. MicroRNA-21 promotes cell proliferation, migration, and resistance to apoptosis through PTEN/PI3K/AKT signaling pathway in esophageal cancer. Tumour Biol 2016; 37: 12061-70.

29. Jing X, Cheng W, Wang S, Li P, He L. Resveratrol induces cell cycle arrest in human gastric cancer MGC803 cells via the PTEN-regulated PI3K/Akt signaling pathway. Oncol Rep 2016; 35: 472-8. 